\section{BASEMENT MEMBRANE DEGRADATION BY GASTRIC AND OESOPHAGEAL CANCER CELLS : THE EFFECT OF PLASMINOGEN}

DE Hewin. T Lai, MN Vipond. D Alderson.

Department of Surgery. Bristol Royal Infirmary. Bristol BS2 8HW

Proteolytic degradation of the basement membrane allowing tumour cell invasion is an important process in the development of metastases. The conversion of plasminogen to the active protease plasmin by urokinase plasminogen activator is thought to be a key step in initiating proteolysis. This process was investigated in human oesophageal and gastric carcinoma cell lines using an in vitro invasion model.

Isotope-labelled subendothelial cell basement membranes were prepared by incubating human umbilical vein endothelial cells in the presence of $\left[{ }^{3} \mathrm{H}\right]$ serine $(5 \mu \mathrm{Ci} / \mathrm{ml})$. Two oesophageal (KYSE 140, KYSE 30 ) and two gastric (AGS, HGC-27) carcinoma cell lines were seeded onto the membranes and grown in the presence or absence of plasminogen $(40 \mu \mathrm{g} / \mathrm{ml})$. Degradation was determined by the measurement of activity released into the supernatant at $24 \mathrm{hr}$ intervals. (Results are shown as median counts per minute.)

\begin{tabular}{|l|c|c|c|c|c|c|}
\cline { 2 - 7 } \multicolumn{1}{c|}{} & \multicolumn{2}{c|}{$24 \mathrm{~h}$} & \multicolumn{2}{c|}{$\mathbf{4 8 ~ h}$} & \multicolumn{2}{c|}{$\mathbf{7 2 ~ h}$} \\
\hline plasminogen & - & + & - & + & - & + \\
\hline controls & 578 & 598 & 667 & 697 & 602 & 705 \\
\hline KYSE 140 & 1670 & $3594^{*}$ & 2107 & $3235^{*}$ & 1991 & $2882^{*}$ \\
\hline KYSE 30 & 4172 & $6233^{*}$ & 3653 & $4797^{*}$ & 2984 & $3627^{*}$ \\
\hline AGS & 616 & $796^{*}$ & 676 & $949^{*}$ & 751 & $1064^{*}$ \\
\hline HGC-27 & 1498 & $2633^{*}$ & 2167 & $2916^{*}$ & 2127 & $2831^{*}$ \\
\hline
\end{tabular}

${ }^{*} \mathrm{p}<0.05$ (Mann-Whitney test) - cells with vs. cells without plasminogen

Plasminogen significantly increased basement membrane degradation by all cell lines. These data support the hypothesis that tumours of the upper gastrointestinal tract utilise plasminogen in the degradation of basement membranes during invasion.
THE SIGNIFICANCE OF CRYPTOLYTIC LESIONS IN IXTLAMATORY BOWEL DIsEAst. I D Lee, C Maguire, Obeidat, R I Russell. Departments of Pathology and Gastroenterology, Glesgow Royal Infirmary, scotland

colorectal biopsy plays a crucial role in the differential diegnosis of inflammatory bowe- disease. In mazy ceses assessment has to be based on mucosal alterations which are often non specific. "Cryptolytic colitis" describes the finding of crypt related epithelloid granulomes. These lesions may sccur in the abserse of more discrete non crypt related Lamina propria granilomas which are the hallmark of Crohn's disease. At present the significance of thase pericryptal granulomas is unknown.

AIM: To investigate the hypothesis that patients with "cryptolytic colitis" have a high probability of subsequently developing unequivocel evidence of Crohn's disease. METBODs: 14 patients with "cryptolytic colitis" on initial rectel or colonic biopsies were studied. (Group A) Mons of these patiente had any evidezce to suggest a diagnosis of Crohn's disease. For comparative purposes 8 patients with pericryptel inflamation but no granuloma formation were also assessed. (Group B) All subsequent histology specimens were examined ard the progress of the patients reviewed over a period of 2-17 years. Crohn's disease was diagnosed in those patients developing discrete non crypt related granulomas or evidence of ama'l bowel involvement.

10 of 14 patients with "cryptolytic colitis" (Group A) were subsequently disgnosed as having Crohn's disease compared with 1 of 8 patients with pericrypial

inflammatory chenges. (Group B) Five patients in Group A developed small bowel involvement, six required surgical interventions, and six had nutritional problems.

coxclusios - Patients with "cryptolytic colitis" have a high probability of subsequently developing Crohn'a disease and any surgery reguired in these patients should be planned accordingly.

\title{
Inflammatory bowel disease T82-T90
} PLATELET AGGREGATE FORMATION IN THE
MESENTERIC MICROCIRCULATION IN CROHN'S DISEASE: FURTHER EVIDENCE FOR THEIR ROLE IN PATHOGENESIS.

CE Collins, J Rogers, C Hall*, RKS Phillips*, PR Hawley*, NS Williams. DS Rampton. GI Science Research and Surgical Units, The London Hospital Medical College. and *Department of Surgery, St Mark's Hospital. London.

Mesenteric microvascular thrombosis may be an early pathogenic event in Crohn's disease (CD), and intravascular platelet aggregates have been identified in mucosal biopsies in ulcerative colitis (UC). Activated platelets are involved in thrombogenesis and exhibit inflammatory properties. In active inflammatory bowel disease (IBD) increased numbers of platelet aggregates are detectable in the peripheral circulation. We tested the hypothesis that in IBD, platelet aggregation is triggered in the mesenteric vasculature.

METHODS: We measured platelet aggregate ratio (using a modified Wu and Hoak's method) and platelet count in blood samples taken into EDTA from the mesenteric arterial and venous circulations during intestinal resection in patients with $\mathrm{CD}(n=7), \mathrm{UC}(\mathrm{n}=6)$ and controls (colon carcinoma, $n=6$ ).

RESULTS: expressed as median (interquartile range) platelet aggregate ratio platelet count $\left(x 10^{9} / \mathrm{n}\right)$

\begin{tabular}{|c|c|c|c|c|}
\hline & arterial & venous & anterial & \\
\hline & & & & \\
\hline & $.96(.95-.97)$ & $.94(.92-.95)$ & $24+(23(--357)$ & $245(190-323)$ \\
\hline controls & $1.011 .92-1.03)$ & $.99(.98-1.00)$ & $203(233-355)$ & $251(216-332)$ \\
\hline
\end{tabular}

* $\mathrm{p}<0.05$ compared to artery, $\div \mathrm{p}<0.01$ for arteriovenous difference compared to UC and controls.

Arteriovenous differences between platelet aggregate ratios (lower indicating increased numbers of aggregates) were greater in $\mathrm{CD}$ than in $\mathrm{UC}$ or in controls.

CONCLUSIONS: Numbers of platelet aggregates are increased on the venous side of the intestinal circulation in $C D$, indicating that the aggregates detectable in the peripheral circulation arise within the mesenteric vasculature. The finding supports the proposal that local aggregation of platelets may contribute to intestinal microinfarction and local inflammation in $\mathrm{CD}$.
HLA CLASS II GENES ARE IMPORTANT DETERMINANTS OF DISEASE SUSCEPTIBILITY IN ULCERATIVE COLITIS, BUT NOT IN CROHN'S DISEASE J Satsangi, KI Welsh, M Bunce, JI Bell, DP Jewell

Nuffield Departments of Medicine and Surgery at the Oxford Radcliffe Hospitals

Introduction The importance of HLA Class II genes in the pathogenesis of Crohn's disease and ulcerative colitis remains controversial. Although recent linkage studies from Northern Europe have demonstrated no linkage with microsatellite markers in the HLA region, these studies have assumed simple Mendelian inheritance pattern for both Crohn's disease and ulcerative colitis which may not be valid. Non-parametric methods of analysis, such as the comparison of allele sharing in affected siblings are more suited to complex polygenic diseases.

Subjects 72 families in whom two or more siblings have inflammatory bowel disease were identified. A total of 83 sibling pairs were available: in 29, both siblings had ulcerative colitis; in 42 both siblings had Crohn's disease; and in 12 pairs, 1 sibling had Crohn's disease, the other ulcerative colitis. In total, 152 affected relatives and 162 healthy first degree relatives were studied.

Methods HLA DRB1 and DQB gene typing was performed by PCR (polymerase chain reaction) using sequence specific primers (PCR-SSP).

Results Of 29 affected sibling pairs with ulcerative colitis, 15 shared two DRB DQB haplotypes, and only one pair of siblings shared zero haplotypes. Comparison of the number of sibling pairs sharing zero and two haplotypes identical-by-state provided strong evidence of linkage in ulcerative colitis with the DRB DQB haplotype $\left(\chi^{2}=5.27, \mathrm{p}=.016\right)$ and the DRB1 locus $\left(\chi^{2}=5.32, \mathrm{p}=\right.$ .017 ). In Crohn's disease, no evidence for linkage with the Class II genes was present when allele sharing amongst sibling pairs was compared. Of the 42 sibling pairs with Crohn's disease, 2 shared two DRB1 DQB haplotypes, 8 shared zero, and 22 shared one haplotype.

Conclusions HLA Class II genes are important determinants of susceptibility, and phenotype in ulcerative colitis, but not in Crohn's disease. Together with the reported concordance rates in twins and siblings, the present data suggest that HLA genes may account for at least $60 \%$ of inherited susceptibility to ulcerative colitis, but less than 10\% in Crohn's disease. 
CYTOKINE GENE POLYMORPHISM IN INFLAMMATORY BOWEL DISEASE: STUDY OF IL-1 $\alpha$ AND II-1RA GENES.

E.Louis, J.Satsangi, M.Roussomoustakaki, G.Fanning, K.Welsh, D.P.Jewell. Gastroenterology Unit, Radcliffe Infirmary, and Transplant unit, Churchill Hospital, Oxford.

Introduction. Alterations in production of interleukin-1a (IL$1 \alpha$ ) and of the interleukin-1 receptor antagonist (IL-1RA) have been strongly implicated in the pathogenesis of mucosal inflammation in Crohn's disease (CD) and Ulcerative colitis (UC). The genes involved in the regulation of these cytokines therefore provide potential candidate genes for suceptibility to Inflammatory bowel disease.

Subjects. $132 \mathrm{UC}, 123 \mathrm{CD}$ and 90 ethnically matched controls. Full historical details, including age of onset, disease extent. need for surgery, were available. Disease extent was

determined by a combination of radiological, endoscopic or histologic data.

Methods. DNA from peripheral blood leucocytes was amplified by the polymerase chain reaction. Polymorphisms, each characterized by a variable number of tandem repeat sequences (VNTR), of intron 6 of the IL-1a gene, and of the intron 2 of the IL-1RA gene were studied. Amplified DNA was visualised after agarose gel electrophoresis. Allele frequencies between patient groups and controls were compared by $\mathrm{X}^{2}$ testing.

Results. IL-1RA VNTR. Allele frequencies were as follows in controls, UC, and CD respectively: $77 \%, 73 \%, 72.5 \%$ for the 400 bp allele; $21 \%, 23.5 \%, 25 \%$ for the 240 bp allele; $2 \%, 2.5 \%, 2.5 \%$ for the $500 \mathrm{bp}$ allele; $0 \%, 1 \%, 0 \%$ for the $300 \mathrm{bp}$ allele. There was no significant difference between controls, UC and CD. Furthermore, no association was present with subgroups defined by disease extent or age of onset.

IL-1a VNTR. Preliminary results on 51 controls, 94 UC and $92 \mathrm{CD}$ do not show any significant difference between groups in the frequency of the $800 \mathrm{bp}, 760 \mathrm{bp}, 1220 \mathrm{bp}$, and 940 bp alleles. More complete results will be presented. Conclusions. These polymorphisms are unlikely to be important in overall susceptibility to UC or CD.
IS THERE A DEFECT IN SULPHUR METABOLISM IN ULCERATIVE COLITIS? M.C.L, Pitcher, E.R. Beatty, R.H. Waring", Cambridge, CB2 2DH: School of Biochemistry, University of Bimingham, Birmingham B15 2TT.

Introduction: Reducing sulphur compounds and phenols are produced within the colonic lumen as products of bacterial fermentation. Sulphation of phenol by the colonic mucosa is impaired in UC, possibly due to defective phenyl sulphotransferase or S-oxidation by cysteine dioxygenase. $\mathrm{H}_{2} \mathrm{~S}$ and mercaptans reproduce the selective metabolic block in butyrate $\beta$-oxidation observed in UC colonocytes and are thought to be detoxified by thiolmethyltransferase (TMT) in the colonic mucosa. TMT activity is largely under genetic control and like sulphotransferase activity, increases distally along the length of the colon. The biochemical properties of enthrocyte TMT are similar to those of other tissue membranes and we have therefore investigated whether of ofter tissue membranes and we have therefore investigated whether
defects of sulphur metabolism exist in UC which might act in conjunction with environmental factors in the expression of disease.

Methods: 21 patients with UC (6 active, 15 remission; 12M, 9F; median age 49y, IQR 38-62y) and 21 healthy controls (9M, 12F; median age 45y, IQR 35-54y) were venesected after an overnight fast. TMT activity was measured in prepared enythrocyte membranes as the extent of conversion of 2-mercaptoethanol to radiolabelled S-methyl-2mercaptoethanol with ${ }^{3} \mathrm{H}$-methyl-S-adenosylmethionine as the methyl group donor. S-oxidation capacity was investigated by measurement of
plasma concentrations of the enzyme substrate (cysteine), by reaction plasma concentrations of the enzyme substrate (cysteine), by reaction
with acid ninhydrin and spectrophotometry at $560 \mathrm{~nm}$, and product (sulphate) by anion exchange chromatography with conductivity detection. The cysteine/sulphate ratio was calculated for each subject. Results were statistically analysed by ANOVA.

Results: TMT activity was elevated in UC patients compared to controls but this was not significant (median [IQR] 3.06 [2.45-3.69] vs. 2.43 [1.80-3.19] $\mathrm{U} / \mathrm{mg}$ protein; $p=0.19$ ). Plasma sulphate was significantly elevated in UC patients with active disease compared to
disease remission and controls $(0.33$ [0.29-0.45] vs. $0.28[0.27-0.31]$ vs. $0.30[0.28-0.33]$ mmoln; $p=0.029$ ) but there was no significant difference in cysteine/sulphate ratio between UC patients and controls ( 0.085 in cysteine/sulphate ratio between UC patien

Conclusions: TMT activity may be induced in UC to detoxify luminal reducing sulphur compounds which increase in concentration distally in the colon. Although inorganic sulphate is freely available to the colonocyte at the serosal side, cellular uptake of sulphate or sulphotransferase activity may be defective in UC leading to impaired mechanisms of detoxfication and reduced sulphation of mucin.

(Acknowledgements to NACC, Addenbrooke's NHS Trust and Peel Medical Research Trust for financial support).
Lymphocyte homing molecules in the normal and inflamed gut. Nakamuta K, Jewell DP and Bloom SL. Department of Gastroenterology, Radcliffe Infirmary, Oxford, UK.

Background. Memory (CD45RO) lymphocytes which have been exposed to antigens in the gut can recirculate to the gut following antigenic rechallenge This may be important in the pathogenesis of inflammation in IBD. To study adhesion molecules which may mediate homing of memory $T$ cells, we have compared the expression of adhesion receptors on naive and memory lymphocytes in peripheral blood (PBL), intestinal lamina propria (LPL) and intraepithelial lymphocytes (IEL) from patients with and without inflammaton bowel disease. Methods. PBL, LPL, and IEL were isolated from 10 patients undergoing colectomy for ulcerative colitis, 11 patients having resections for colonic Crohn's disease, and 17 controls who were undergoing resection for colonic cancer. Purity of IEL was established by measuring CD4/CD8 ratios only those samples with a ratio of less than 0.4 were used. PBL. LPL and IEL were analysed by dual colour flow cytometry for naive (CD45RA) and memon (CD45RO) phenotype and expression of $\alpha_{\text {IEL }} \beta_{7}$ integrin, $\alpha_{4}$ integrin, CD31, L-Selectin, and LFA-1. All experiments were done on total lymphocite populations and also after $\mathrm{B}$ cell depletion using CD19-conjugated dynabeads Cells were gated using CD14-conjugated dynabeads to exclude monocytes and macrophages. Results for UC and CD were compared with each other and normal controls using Mann-Whitney testing. Results. Expression of $\alpha_{4}$ integrin was reduced on IEL in UC compared with controls. compatible with a change in $\alpha$ integrin from $\alpha_{4}$ to $\alpha_{\text {IEL }}$. Expression of $\alpha_{\operatorname{IEL}} \beta_{7}$ was highest on memory cells, with IEL $>$ LPL $>$ PBL. Naive and memory LPL showed a similar expression in control and UC patients, but $\alpha$ IEL $\beta 7$ expression on memor LPL in $C D$ was significantly increased compared with controls $(38.6 \% \pm 6.1$ vs $11.6 \% \pm 1.4, p<0.01)$. CD31 was expressed by more naive than memory cells in all patients, with PBL>IEL $>$ LPL, but no significant differences were seen between controls and IBD patients. Expression of L-Selectin by PBL in CD was slightly but not significantly increased: low expression by memon LPL and IEL is compatible with shedding of L-Selectin by activated lymphocytes. Conclusion. These results support the idea of a population of memory $T$ cells using adhesion receptors such as $\alpha$ IEL $\beta 7$ to home to the intraepithelial compartment where they may mediate cellular cytotoxicity to colonic epithelial cells.

THE BALANCE OF IMMUNOREGULATORY AND PRO-INFLAMMATORY CYTOKINES IN ACTIVE
ULCERATIVE COLITIS: UNTREATED AND IN TREATMENT FAILURE D.Jenkins R. Seth. D McWilliam, A Cole, G. Vautier, R.A. Robins, B.B. Scott* and C.J. Hawkey. Departments of Histopathology. Gastroenterology. and Immunology, University Hospital. Nottingham NG $2 \mathrm{UH}$.

A sensitive Enzyme Linked Oligonucleotide Chemiluminescen Assay (ELOCA) method to guantitate (RT)-PCR products was used to measure mRNA levels of the pro-inflammatory cytokine (ILI), the chemokine IL8. immunoregulatuy cytokines of type 1 (IL2, IFNY) and of type 2 (ILIO. IL 13) in mucosa from li untreated patients with ulcerative colitis (UC) at first presentation. from 8 patients with UC having colectomy for treatment failure and from 14 normal and 12 surgical controls. In untreated acute UC median $\mathrm{mRNA}$ levels of the proinflammatory cytokines ILI and of the chemokine IL 8 were highly and significantly $(p<0.05)$ elevated (IL 1: 0.62: IL8 1.27) compared to normal mucosa (IL 1: 0.05: IL8: 0.06 ). The type 1 cytokine IFNY was also significantly increased (UIC 0.05 ; normal: 0.026 ) but IL 2 was not raised (UC: 0.11 : normal: 0.14 ). The type 2 cytokine $1 \mathrm{~L} 10$ was significantly elevated (UC 0.24: normal: 0.013 ) and IL 13 was also increased (UC: 0.26 normal 0.06 ). In acutely active, failed treatment UC IL 8 was very highly elevated (median7.4) above the level in untreated UC. IFNY (median (). (18), and IIL 10 (median 0.24) were elevated similar to active untreated UC. Unlike untreated UC. ILI and IL 13 were not elevated above normal. IL 2 remained

Measurements of cytokine mRNAs indicate that markedly increased local production of IL1, IL 8 and IFN $v$ may' play an important role in the pathogenesis of active inflammation in untreated UC. The failure to increase IL2 transcription may parallel development of UC-like disease in mice with a disrupted IL 2 gene. Increased $1 \mathrm{LC} 10$ and $\mathrm{IL}^{2} 3$ may act to control the activation of macrophages and production of type followito I 8 and IL 8 and 1 may be important, but there is suppression of ILio levels and other cytokines may contribute to active disease in treatment failure. 
DISTRIBUTION OF DIVIDING T CELLS THROUGHOUT THE BOWEL WALL IN INFLAMPMATORY BOWEL DISEASE Fell JME, Walker-Smith JA, Spencer J, MacDonald TT Paediatric Gastroenterology, st Bartholomew's Hospital, London.

The transmural distribution of dividing $T$ cells was examined in ileum and colon of children with inflammatory bowel disease (Crohn's $n=19$, ulcerative colitis $n=7$, controls $n=6$ ) by double-immunohistochemistry using Ki67 to identify proliferating cells and $\mathrm{CD} 3$ to identify $\mathrm{T}$ cells. In ileal lamina propria virtually no $\mathrm{Ki} 67+, \mathrm{CD} 3+$ cells were seen in control tissue or Crohn's disease tissue. Likewise in colonic lamina propria, there were very few $\mathrm{Ki} 67+, \mathrm{CD} 3+$ cells in control tissue, ulcerative colitis tissue or crohn's tissue. In contrast, there were significantly more $(p<0.005) \mathrm{Ki} 67+, \mathrm{CD} 3+$ cells within the lymphoid follicles of ileal and colonic crohn's disease than in the follicles in ulcerative colitis and control tissue (colon: $\mathrm{Cr}$ median 1.28 (range $0.6-3)$; UC $0.15 \%(0-0.5)$; control $0 \%(0-0)$, ileum: $\operatorname{Cr} 0.8 \%(0.1-1.8)$; control $0.2 \%(0-0.5)$ ) Increased numbers of $\mathrm{Ki} 67+, \mathrm{CD} 3+$ cells were present in the submucosa, muscle layers (M) and serosa in Crohn's ileitis and colitis compared to the lamina propria (LP), although only in the muscle of the colon was the difference statistically significant (LP: $0.48(0-1)$; M: $1.6 \%(0-5.2) \quad p=0.03)$. Pooling data from ileal and colonic Crohn's disease however did show significantly increased $\mathrm{Ki} 67+, \mathrm{CD} 3+$ cells in all deeper layers of the intestine compared to the lamina propria. The demonstration of dividing $T$ cells in the deeper layers of the intestine in Crohn's disease suggests that chronic cell-mediated inflammation may be responsible for the transmural nature of this disease.
T91

\section{FAMILY BASED COLORECTAL CANCER SCREENING IN A} DISTRICT HOSPITAL.

NPJ Cripps, RJ Heald (introduced by RJ Leicester).

Colorectal Research Unit, C Floor, North Hampshire Hospital NHS

Trust, Aldermaston Road, BASINGSTOKE, Hampshire. RG24 9NA

Colorectal cancer (CRC) screening using family history (FH) to define the highest risk group has been proven in dominant CRC pedigrees and in a teaching hospital population. We aimed to validate FH based screening in a district hospital population and to identify which groups would be most profitably screened.

396 individuals aged over 25 with at least one first degree affected relative were screened using a single slide, immunological faecal occult blood test (FOBT) and FH data to select the highest risk group. Compliance overall was $64.9 \%$ but was significantly better if contact with the individual was made within one year of diagnosis of the index relative $\left(75 \%\right.$ v. $62.1 \%, \chi^{2}=5.7,1$ d.f., $\left.p<0.05\right)$.

Colonoscopy was recommended for positive FOBT or if the lifetime risk was $\geq 1: 10$. Only 4 individuals from 2 families were potentially in a dominant pedigree. 100 colonoscopies were indicated by the protocol; 24 for positive FOBT ( $6.1 \%$ of tests) and 78 for lifetime risk ( 2 for both reasons). 12 individuals with adenomas were detected ( $13.2 \%$ of those colonoscoped), at least 3 of which were at high risk of malignant transformation. No cancers were diagnosed. The majority of screenees were younger than $55(67.8 \%)$; these accounted for the majority of colonoscopies (68.1\%) but only 1 large adenoma was diagnosed in this group. Adenomas were diagnosed in 6 of 20 completed colonoscopies for positive FOBT compared with 6 of 71 for high lifetime risk $\left(\chi^{2}=4.59\right.$ with Yates' correction; 1d.f., $\left.p<0.05\right)$. Only 1 adenoma, which was diminutive, would not have been detected had flexible sigmoidoscopy been preferred for colonic examination for high lifetime risk. Each adenoma patient cost $£ 1,250$ to diagnose.

Family-based CRC screening is practical in this setting. The specific FOBT was particularly useful in this protocol. Screening, even in those at moderately increased risk because of family history, should be focused on the older age groups, probably those over 40 years.
Crohn's disease patients suffering from peripheral arthritis or ankylosing spondylitis reveal restricted $T$ cell receptor $V \beta$ regions in different temporal phases of disease. N. Lügering, $R$. Stoll, $M$ Fisahn. T. Kucharzik, W. Domschke. Department of Medicine B, University of Münster, 48129 Münster, Germany.

Little is known about the mechanisms triggering and controlling both the development and perpetuation of extraintestinal complications in Crohn's disease. The aim of the present study was to test the hypothesis that the T-cell immune response in Crohn s disease patients suffering from joint complications may be altered when comparing with patients without extraintestinal manifestations

We used a semiquantitative polymerase chain reaction assay to analyse the $\mathrm{T}$-cell antigen receptor repertoire in peripheral blood $\mathrm{T}$ cells of eight Crohn's disease patients with peripheral arthritis and ankylosing spondylitis and twelve healthy, unrelated controls. Being concerned that different patterns may be seen in different phases of the inflammatory disease process. we have also taken care to analyse sequential samples at various time points of the disease

Expression of all $22 \mathrm{~V} \beta$ genes was found in each healthy control tested and showed no major var ition over time. In contrast, southern hvbridization analysis of amplified products revealed a highly restricted $V \beta$ repertoire in all Crohn's disease patients suffering from peripheral arthritis and ankylosing spondylitis. Our longitudinal studies confirmed variable $V \beta$ usage over time, as certain transcripts were found only in distinct temporal phases of disease.

The fact that in patients with Crohn's disease suffering from joint complications different patterns of $V \beta$ sequences could be temporarily found implies that $T$ cells in Crohn's disease expressing different TCR gene products may interact with different superantigens or different regions of a superantigen, each of which interacts with a distinct spectrum of $\mathrm{V} \beta$-bearing $\mathrm{T}$ cells
ASSESSMENT OF THE INCIDENCE AND PRESENT MANAGEMENT OF RECTAL BLEEDING (BPR) BASED ON PATIENT QUESTIONNAIRES

J.A.Thompson, C.L.Pond, B.Ellis, A.Kenyon, D.Prytherch, M.R.Thompson

Queen Alexandra Hospital, Cosham, Portsmouth, Hants, PO6 $3 \mathrm{LY}$.

Specialists frequently advise a change in policy for investigating BPR. However there is little evidence that this would improve its management and it might cause an urmanageable increase in wurkload. To help develop realistic guidelines for the management of BPR, a validated questionnaire was sent to 6,000 randomly allocated people in three general practices to determine the number having BPR each year, the number seeing their GPs and referred to hospital.

678 replied. 178 (709) had BPR in the previous year. Bleeding occurred more of ten in patients under 49 years of age. 415/1.968 (21\%) compared wi th over 50, 294/2,038 $(14.4 \%)$ and in women aged 16-39, 172/715 (24.1\%) compared with an age matched group of men, 97/571 (16.5\%).

18.18 had dark red bleeding. 12.48 had bleeding wi thout perianal symptoms. 49.18 had an associated change in bowel habit. ( 30.38 hard stools, $18.8 \%$ loose stools).

197 (27.8\%) of patients consul ted their GPs of whom 51 (25.98) were referred to hospital. Thus only $7.1 \%$ of all patients wi th BPR are at the moment referred to hospital.

Conclusion At the moment patients referred to hospital for investigation of rectal bleeding are a highly selected sub-set of the total population of bleeders. Advocates of a change in the present policy for investigating BPR should be aware of these basic facts. 
SCREENING FOR COLORECTAL CANCER BY FLEXIBLE SIGMOIDOSCOPY

B M Goudie, Z Abbass, $\mathrm{K}$ Vaidya, M Lopez, C R Pennington. Department of Clinical Pharmacology, Ninewells Hospital and Medical School, Dundee.

Colorectal cancer is common and the cause of death of the majority of affected patients. Screening asymptomatic middle aged individuals for polyps or early cancer may prevent or cure this disease. Flexible sigmoidoscopy can detect $70 \%$ of adenomatous polyps. At present there is no policy for routine screening in the UK.

The aim of this study was to assess uptake of screening and to establish the detection rate of premalignant or malignant lesions by flexible sigmoidoscopy in patients with no known colonic disease living in an area with a high prevalence of colorectal cancer.

The target population comprised patients age 51-60 years registered with one general practice. Each patient received a letter describing the problem of colorectal cancer and the rational for screening and a covering letter from their general practitioner. A response sheet was included in which they were given the option of an examination or a consultation to receive additional information.

Letters were posted to 302 patients, 10 were returned as the subject had moved. Replies were received from 183, 74 requested an examination. 69 were invited to attend and 5 await an appointment, 12 cancelled their appointment. 57 underwent sigmoidoscopy of whom 10 had adenomatous polyps. Diverticular disease was evident in 14, 29 examinations were normal, and no patient had cancer.

There was a significant prevalence of adenomatous polyps in patients undergoing flexible sigmoidoscopy. However uptake of screening was sub-optimal with the method of recruitment used in this study.

\section{RESTORATIVE PROCTOCOLECTOMY IN CHILDREN AND} YOUNG ADULTS

J Romanos, N J McC Mortensen, MGW Kettlewell and DP Jewell Departments of Colorectal Surgery and Gastroenterology John Radcliffe Hospital, Oxford

There are few reports of restorative proctocolectomy in children and young adults. We have reviewed the results in 5 male and 9 female patients (median age 15.8, range 6.3-17.5). Nine were operated on for ulcerative colitis (UC), 2 for indeterminate colitis (IC), 2 for familial adenomatous polyposis (FAP) and 1 for functional problems. In UC and IC patients, acute severe attack was the indication for surgery in seven and failed medical treatment in four.

In 2 patients (IUC-1FAP) proctocolectomy, pouch and ileostomy was performed and of the remaining, 10 have had completion proctectomy, pouch and ileostomy and 2 (UC) completion proctectomy and pouch without a covering ileostomy. A J-pouch was constructed in 10 patients and the rest were $W(3)$ and $S$ (1) pouches. Seven patients have had stapled and 7 hand-sewn anastomosis. Six patients had mucosectomy and in 10 the entire anal canal was preserved.

There was no mortality. Thirty day morbidity was $35.7 \%$ (one patient developed depression, anorexia. Two reoperations; for pouch haemorrhage and for small bowel obstruction). In the long term 9 complications developed in 7 patients ( 3 small bowel obstruction; 2 fistula; 1 anal stenosis). In 2 patients revision of the pouch was performed ( 1 for poor function, 2 for pelvic sepsis-fistula)

The median follow up was 43 months (range 2 to 87 ). The median daytime stool frequency was 4.5 (range 1.5-8.5) and nocturnal 0 (range 0-1.5). Two patients complained of major and 1 minor incontinence, and one had urgency. Nine were able to discriminate flatus from liquid or semi-solid stools. Three are still on antidiarrhoeal drugs. All patients had normal bladder function. Six patients of 11 with UC-IC (54\%) presented with pouchitis of a median duration of 4 weeks (range 1-24) which was successfully treated with oral antibiotics and steroids enemas.

Although morbidity is high, restorative proctocolectomy remains an important surgical alternative for younger patients with UC and FAP. It improves quality of life by avoiding permanent ileostomy whilst providing satisfactory functional results.
DISTURBED CD44 GENE ACTIVITY IN COLORECTAL CARCINOMA - A NEW ABNORMALITY WITH CLINICAL DIAGNOSTIC POTENTIAL

K Yoshida, BF Warren, J Boldeoku, T Sugino, S Goodison, T Toge, E Tahara, D Tarin

Nuffield Department of Pathology, and Department of Cellular Pathology, John Radcliffe Hospital, Oxford and Hiroshima University

CD 44 is a cell adhesion molecule over expression of which is found in a variety of carcinomas, including ones of the stomach, colon, bladder, prostate, uterus, lung and breast. The gene consists of twenty exons, ten of which can be alternatively assembled to make a variety of protein isoforms. Previous work has demonstrated that abnormal assembly and overproduction of the products of these exons is a hallmark of neoplasia in several organs and could be important in evaluation of prognosis. We have also shown that non-invasive diagnosis of bladder carcinoma is possible by detection of unusual activity of this gene in exfoliated cells in urine.

The present study analysed CD 44 gene expression in cell lines from 14 oesophageal carcinomas, 3 colonic carcinomas, 3 breast carcinomas and fresh tissue from 20 colorectal carcinomas using reverse transcription followed by the polymerase chain reaction.

It was confirmed that there was abnormal assembly of several exons of the gene. However, a unique new finding was that noncoding sections of the gene (intron 9 transcripts) were detected in RNA from 11 oesophageal carcinomas, 3 colorectal carcinomas and 1 breast carcinoma cell line. This was confirmed by RNase and DNase digestion. Introns were detected in both nuclear and cytoplasmic mRNA fractions suggesting that abnormal splicing of pre-mRNA occurs in cancer cells. The abnormal retention of intron 9 was confirmed in $16(80 \%)$ fresh colorectal tumour samples but there was no correlation with Dukes' stage.

The clinical significance of these findings is that abnormalities of CD44 expression are useful early diagnostic markers of neoplasia. Intron 9 expression is a unique new marker of malignancy. The priority is now to use the exceptional sensitivity of these molecular techniques for early non invasive tumour detection using colon washings or stool samples.

THE POSTERIOR COLPORRHAPHY: A COSMETIC OR A THERAPEUTIC PROCEDURE? M A Kahn, S L Stanton (introduced by D Kumar), St. George's Hospital, London

OBJECTIVES: To determine the cure rate of posterior colporrhaphy and its effect on bowel and sexual function at 5 year follow up. METHODS: The notes of 231 patients who underwent 244 posterior colporrhaphies between 1.1 .89 and 4.1.94 were reviewed. $171(74 \%)$ were interviewed; $140(61 \%)$ were examined. Mean followup time was 42.5 months (range 11-74). RESULTS: The mean age was 56 years (range 27-83); mean number of vaginal deliveries was 3 (range 0-8). 209 patients had prior or concurrent vaginal and/or bladder neck surgery including 37 previous posterior colporrhaphies.

\begin{tabular}{|c|c|c|c|}
\hline $\begin{array}{l}\text { Symptoms } \\
\qquad N=171\end{array}$ & $\begin{array}{l}\text { n } \\
\text { pre } \\
\text { op }\end{array}$ & $\begin{array}{c}n \\
\text { post } \\
\text { op }\end{array}$ & $\begin{array}{c}\% \\
\text { de } \\
\text { novo }\end{array}$ \\
\hline Lump \pm pressure $(L \pm P)$, all & 109 & 53 & 30 \\
\hline $\mathrm{L} \pm \mathrm{P}$, rectocele only, $(\mathrm{n}=140)$ & $51^{\circ}$ & $32^{\circ}$ & 48 \\
\hline Incomplete bowel emptying & 46 & 65 & 58 \\
\hline Constipation & 38 & 56 & 70 \\
\hline Incontinence faeces & 7 & 18 & 80 \\
\hline Incontinence flatus only & unknown & 32 & -.. \\
\hline Vaginal \pm perineal splinting & unknown & 57 & -.- \\
\hline Manual emptying & unknown & 40 & -.- \\
\hline Sexual dysfunction & 30 & 47 & 70 \\
\hline
\end{tabular}

$62 \%$ felt that they improved after surgery. $12 \%$ felt that their inability to defaecate recurred or worsened. Additional post operative symptoms included: haemorrhoids $(27 \%)$, rectal bleeding (16\%), soiling and/or inability to wipe clean (33\%), rectal and/or vaginal pain (22\%), faecal urgency $(13 \%)$, and diarrhoea (13\%). 33 patients had moderate or marked rectocele, of whom 7 had no symptoms of impaired bowel emptying. CONCLUSIONS: Posterior colporrhaphy corrects the vaginal defect in $80 \%$ of patients. It does not necessarily correct and may contribute to bowel and sexual dysfunction. Conversely, the presence of the anatomical defect does not imply dysfunction. 
DETECTION OF ANTINEUTROPHIL CYTOPLASMIC ANTIBODY IN PRIMARY SCLEROSING CHOLANGITIS : COMPARISON OF THE ALKALINE PHOSPHATASE AND IMMUNOFLUORESCENT TECHNIQUES. D Bansi ${ }^{1}, K$ Boberg ${ }^{2}$,

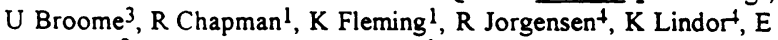
Schrumpf $^{2}$. John Radcliffe Hospital ${ }^{1}$, Oxford, UK. The National Hospital ${ }^{2}$, Oslo, Norway. Huddinge Univ. Hospital ${ }^{3}$, Huddinge, Sweden. Mayo Clinic ${ }^{4}$, Rochester, USA

The variation in prevalence of antineutrophil cytoplasmic antibodies (ANCA) in primary sclerosing cholangitis (PSC) may be methodological. To resolve this issue we compared the sensitivity (true pos.true pos.+false neg. ratio) and specificity (true neg.true neg.-false pos.ratio) of the indirect alkaline phosphatase (IALP) and immunofluorescence (IF) techniques. Method: Sera from 3 centres were tested blinded on alcohol-fixed neutrophils using both techniques. Patients; USA:14 PSC, 14 primary biliary cirrhosis (PBC); Sweden:32 PSC, 3 autoimmune hepatitis (AIH), 14 PBC,11 chronic liver disease; Norway: 32 PSC, 14 AIH, 13 PBC, 1 hep. C. 36 normals and positive and negative controls were included.

Results: Sensitivity and specificity of ANCA for PSC (excl. controls)

\begin{tabular}{|c|c|c|c|}
\hline IALP method & USA & Sweden & Nonway \\
\hline Sensitivity & $10 / 1+(71 \%)$ & $21 / 32(66 \%)$ & $22 / 32(69 \%)$ \\
\hline Specificity & $13 / 1+(93 \%)$ & $27 / 28(96 \%)$ & $13 / 28(46 \%)$ \\
\hline If method & USA & Sweden & Norway \\
\hline Sensitivity & $7 / 14(50 \%)$ & $18 / 32(56 \%)$ & $15 / 32(47 \%)$ \\
\hline Specificitv & $12 / 1+(86 \%)$ & $2+/ 28(86 \%)$ & $17 / 28(61 \%)$ \\
\hline
\end{tabular}

Overall IALP sensitivity was $53 / 78(68 \%)$ and specificity $53 / 70$ (76\%), compared with $40 / 78(51 \%)$ and $53 / 70(76 \%)$ for IF respectively. Conclusions: Overall the IALP method of ANCA detection has greater sensitivity and equal specificity to IF for serological diagnosis of PSC. We recommend use of this method which is also easier to interpret. Future identification of the antigen(s) should allow development of a more sensitive and specific diagnostic assay for PSC
T99

\section{ACTIONS OF CARVEDILOL, A VASODILATING BETA- BLOCKER, UPON SPLANCHNIC AND RENAL HAEMODYNAMICS IN PATIENTS WITH CIRRHOSIS.} Forrest EH, Bouchier IAD, Hayes PC. Department of Medicine, The Royal Infirmary, Edinburgh.

Propranolol reduces variceal haemorrhage in portal hypertension but deterioration in renal function may occur in some patients. Alpha-adrenergic overactivity has been suggested as a mediator of the renal impairment of cirrhosis. We investigated the haemodynamic actions of Carvedilol, a non-specific beta-blocker with alpha-1 antagonism, upon the splanchnic and renal circulations of patients with cirrhosis.

Methods: Twelve patients with alcoholic cirrhosis $(9 \mathrm{male})$ were studied. Free and wedged hepatic vein pressures (FHVP and WHVP), azygos blood flow (AzBF), and unilateral renal vein flow [(RVF); direct reverse thermodilution method], heart rate (HR), and mean arterial pressure (MAP) were measured before and 60 minutes after $25 \mathrm{mg}$ oral Carvedilol.

Results:

\begin{tabular}{c|c|c|} 
Time $(\mathrm{min})$ & 0 & 60 \\
\hline HR $(\mathrm{bpm})$ & $81.3(3.2)$ & $73.8(4.8)$ \\
\hline MAP(mmHg) & $95.7(5.3)$ & $84.5(5.2)^{*}$ \\
\hline HVPG $(\mathrm{mmHg})$ & $16.8(1.0)$ & $14.1(1.1)^{* *}$ \\
\hline A2BF $(\mathrm{mV} / \mathrm{min})$ & $440(93)$ & $410(90)$ \\
\hline RVF $(\mathrm{ml} / \mathrm{min})$ & $354(119)$ & $323(84)$
\end{tabular}

Mean (SEM); Hepatic venous pressure gradient (HVPG)=WHVPFHVP; ${ }^{*} p<0.001,{ }^{* *} p<0.0005$ compared to baseline.

Conclusion: Carvedilol has a significant portal hypo censive effect but unlike propranolol does not significantly reduce portosystemic collateral flow. Despite a fall in MAP, renal perfusion was maintained. Carvedilol may be a useful therapeutic tool in portal hypertension by avoiding some of the complications of propranolol.
SERUM FROM PATIENTS IN FULMINANT HEPATIC FAILURE ENHANCES HEPATOCYTE FUNCTION IN CULTURE

J Dillon', E Ekevall2, MD Smith², K Anderson'2, MH Grant², J Gaylor ${ }^{2}$ and PC Hayes' Dept of Medicine', Edinburgh University, Edinburgh EH3 9YW and Bioengineering Unit ${ }^{2}$, Strathclyde University, Glasgow G4 0NW.

A hybrid artificial liver support device for treatment of patients in fulminant hepatic failure (FHF) based on primary cultures of hepatocytes is being developed. For successful implementation of this technology, hepatocytes in culture must remain viable and functional during exposure to the toxins present in FHF serum. We have investigated the effect of 4h exposure to pooled samples of FHF and normal serum on the viability (assessed by lactate dehydrogenase leakage), urea synthesis, total cytochrome P450 content and the profile of hydroxylated testosterone metabolites generated by P450 dependent monooxygenases in primary cultures of rat hepatocytes $24 \mathrm{~h}$ after seeding the cells $\left(1.2 \times 10^{5} \mathrm{cells} / \mathrm{cm}^{2}\right)$ in serum-free Chee's medium. Serum was obtained from patients with FHF from paracetamol poisoning who fulfilled the criteria for liver transplantation. 20h after exposure to FHF serum the viability of hepatocytes was not different to that of cells exposed to normal serum (viability $79.5+/-3.4 \%(n=8)$ compared with $75.0+/-2.8 \%(n=7)$ ). Control cells cultured in Chee's medium formed 141.8 $+/-26.0(n=8)$ nmoles of urea per hour $/ 10^{6}$ cells when challenged with ammonia. After exposure to FHF serum there was an increase in urea production to 158 $+1.21 \%$ above control values $(n=8)$. In contrast, treatment with normal serum decreased urea synthesis to $69+/-8 \%(n=8)$ of controls. Cytochrome P450 content of control cells in Chee's medium was 0.10 $+1-0.01 \mathrm{nmol} / 10^{6}$ cells $(n=7)$. Exposure to normal serum for $4 \mathrm{~h}$ did not alter this $\left(0.10+/-0.01 \mathrm{nmol} / 10^{6}\right.$ cells, $\left.\mathrm{n}=8\right)$, whereas exposure to FHF serum caused a marked increase $\left(0.15+/-0.02 \mathrm{nmol} / 10^{6}\right.$ cells, $\left.n=7\right)$. This increase in $\mathrm{P} 450$ content was not accompanied by an increase in total $\%$ testosterone metabolised after FHF serum treatment, although changes in the metabolite profile pattern were observed. These preliminary data show that hepatocyte function is enhanced during exposure to FHF serum and viability is retained.
PRIMARY SCLEROSING CHOLANGITIS (PSC): STANDARDLIVER FUNCTION TESTS DURING LONG TERM TREATMENT WITH URSODEOXYCHOLIC ACID (UDCA) AND VALUE OF SERIAL QUANTITATIVE LIVER FUNCTION TESTS

M. Mahl, J. v. Schönfeld, N. Breuer, H. Goebell (introduced by D.L. Wingate). Dept. of Gastroenterology, Medical Clinic, 45122 Essen, FRG

In short term studies, UDCA has been shown to improve standard liver function tests in patients with PSC. We prospectively investigated a) the long term effects of UDCA on standard liver function tests and b) the value of serial determinations of galactose elimination capacity and indocyanine green halflife.

For 3 or 4 years, a total of 11 patients (23-57 years, 9 men, 10 with inflammatory bowel disease) were treated with UDCA $(10 \mathrm{mg} / \mathrm{kg}$ bw/d). Before therapy and then every 12 months, standard and quantitative liver function tests were performed. Galactose elimination capacity (GEC) and indocyanine green halflife (ICG) were measured after i.v. administration of $0.5 \mathrm{~g} \mathrm{galactose} / \mathrm{kg}$ bw and $0.5 \mathrm{mg} \mathrm{ICG} / \mathrm{kg} \mathrm{bw}$. GEC and ICG were also measured once in 14 volunteers (Mean $\pm S E, * p<0.05$ compared to values before therapy).

\begin{tabular}{llllll} 
& before tx & 1 year & 2 years & 3 years & 4 years \\
\cline { 2 - 6 } Bilinubin [mg/dl] & $0.9 \pm 0.1$ & $0.9 \pm 0.2$ & $0.9 \pm 0.2$ & $1.8 \pm 0.8^{*}$ & $1.2 \pm 0.4$ \\
AP [U/l] & $761 \pm 203$ & $393 \pm 138^{*}$ & $412 \pm 128^{*}$ & $484 \pm 180^{*}$ & $371 \pm 145^{*}$ \\
gGT [U//] & $285 \pm 80$ & $122 \pm 56^{*}$ & $130 \pm 101^{*}$ & $101 \pm 25^{*}$ & $94 \pm 33^{*}$ \\
AST [U/] & $26 \pm 5$ & $17 \pm 2^{*}$ & $17 \pm 3^{*}$ & $23 \pm 6$ & $20 \pm 5$ \\
ALT [U/] & $55 \pm 10$ & $26 \pm 4^{*}$ & $26 \pm 4^{*}$ & $28 \pm 5^{*}$ & $34 \pm 11^{*}$ \\
GEC [mg/kg/min] & $7.2 \pm 0.9$ & $6.7 \pm 0.4$ & $6.0 \pm 0,3$ & $6.4 \pm 0.5$ & $6.0 \pm 0.8$ \\
ICG [min] & $4.7 \pm 0.7$ & $4.2 \pm 0.5$ & $4.4 \pm 0.4$ & $4.2 \pm 0.5$ & $3.7 \pm 0.6$
\end{tabular}

Parameters of synthetic function of the liver (serum protein, albumin, cholinesterase activity, prothrombin time) did not change over time. GEC and ICG were not significantly different between patients and controls (GEC: $7.0 \pm 0.3$ vs. $7.2 \pm 0.9 \mathrm{mg} / \mathrm{kg} / \mathrm{min}$; ICG: $3.7 \pm 0.3 \mathrm{vs} .4 .7 \pm 0.7 \mathrm{~min}$ ). In the one patient, who died, GEC and ICG did not indicate hepatic failure earlier than standard tests.

We conclude that UDCA significantly improves conventional liver function tests in patients with PSC for several years. Quantitative liver function tests are of little additional value in the timing of liver transplantation in the individual patient. 
LIVER TRANSPLANTATION (LT) FOR HEPATITIS B VIRUS (HBV) INFECTION - PAST, PRESENT AND FUTURE.

M.M. Ahmed, A. Mesheikes, B-H.Ferraz-Neto, M.Hastings, E. Boxall', E. Elias, P. McMaster and D.J. Mutimer. Liver Unit, Queen Elizabeth Hospital, Edgbaston, Birmingham and Regional PHL, Heartlands Hospital, Birmingham.

Refined patient selection and sustained post-transplant immunoprophylaxis with $\mathrm{HBIg}$ have improved graft and patient survival for HBV-associated liver disease. We describe the Birmingham Liver Unit experience since 1987.

Era 1 ('87-'90) - patients with replicative ( $\mathrm{HBeAg}+\mathrm{ve})$ and nonreplicative (anti-HBe+ve) infection were considered suitable for $\mathrm{LT}$ and immunoprophylaxis was given short-term. 11 patients were grafted - 4 perioperative deaths (unrelated to $\mathrm{HBV}$ recurrence), 3 late deaths $(1,2,2$ years post-LT; all $\mathrm{HBeAg}+v e$ pre-LT) due to aggressive $\mathrm{HBV}$ reinfection, 3 survivors $(6,7,7$ years post- $\mathrm{LT})$ with $\mathrm{HBV}$-infected cirrhotic grafts, 1 patient lost to follow-up.

Era 2 ('91-'95) - patients with non-replicative infection (including fulminant HBV) were considered suitable and long-term immunoprophylaxis was used. 14 patients were grafted- 1 perioperative death, 1 late death (aggressive HBV recurrence 8 months post-LT: HBeAg-ve but HBV DNA+ve pre-LT), 12 survivors (median 31, range 3-46 months follow-up). 5 survivors have HBV re-infection immunoprophylaxis stopped because of allergic reactions in 3 patients. strategy failure in 2 patients. 7 patients have non-infected grafts and normal liver function 3-40 months post-LT.

Conclusions (1) Patients with replicative HBV infection are unsuitable transplant candidates - recurrent infection is associated with poor graft and patient survival. (2) Improved graft and patient survival is observed when patients with non-replicative infection receive longterm post-LT immunoprophylaxis, but better strategies are needed. (3) Innovative strategies, including the use of effective antiviral agents preand post-LT, are urgently required for patients with replicative infection.

\section{HEPATIC STELLATE CELLS PRODUCE MEMBRANE-TYPE} MATRIX METALLOPROTEINASE. CJ Hovell, RC Benyon, JE Baker, MJP Arthur. University Medicine, University of Southampton, United Kingdom.

In liver injury and fibrosis there is remodelling of extracellular matrix, which is mediated via production of metalloproteinases by activated hepatic stellate cells (HSC), principally progelatinase $A$. The purpose of this study was to determine if HSC express the newly described enzyme (Sato, Nature 1994;370:61-65), membrane-type metalloproteinase (MT-MMP) which regulates activation of progelatinase $\mathrm{A}$ and thus matrix remodelling in liver.

HSC ( $>90 \%$ pure) were prepared from normal human or rat liver and cultured on plastic for 3-21 days. MT-MMP mRNA in total RNA extracts from HSC was detected by Northern blotting. Indirect immunolabelling for MT-MMP was carried out on viable cells using a biotin labelled secondary antibody and Extravidin-FITC. Western blotting of HSC total protein or cell fractions was performed using the same monoclonal antibody. Human MT-MMP CDNA and antibodies were kindly donated by Dr Sato (Kanazawa University, Japan).

MT-MMP mRNA of $4.5 \mathrm{~kb}$ was expressed by human HSC cultured for 14 and 21 days. Western blotting showed small amounts of MTMMP $(63 \mathrm{kD})$ in SDS lysates of freshly-isolated rat HSC, although there was increased expression by HSC activated by culture for 4,7 , 14 or 21 days. MT-MMP was also detected in lysates of human HSC cultured for 7 days. Immunostaining showed the majority of MTMMP to be associated with the cell surface of HSC. This was further supported by the detection of MT-MMP in the plasma membrane fraction but not the cytosolic fraction of these cells by Western blotting. MT-MMP was also detected in cell-free conditioned media of HSC following 16 hours of culture.

We conclude that HSC express MT-MMP at the plasma membrane. Via activation of progelatinase A, MT-MMP expression will influence and perhaps regulate matrix degradation in liver. This is potentially important in liver injury and fibrosis.
LIVER FAILURE PLASMA CONTAINS INHIBITORS OF HEPATOCYTE PROTEIN SYNTHESIS - RELEVANCE TO EXTRACORPOREAL LIVER SUPPORT .

\section{Selden, E Davies, N Mellor, D Vesey and HJF Hodgson.} Royal Postgraduate Medical School, London W12 ONN

Introduction: An extracorporeal support system to treat patients with Fulminant Hepatic Failure relies both on removing the toxic compounds from plasma and synthesis of relevant proteins such as clotting factors, allowing time for the patient's liver to regenerate. Toxic effects of hepatic failure plasma on protein synthesis have not been explored but are clearly relevant to development of a bio-artificial liver

Aim: To quantify the effect of liver failure plasma on total protein and Factor $\mathrm{V}$ synthesis, in several hepatocyte derived tumour cell lines: HuH7, Hep G2 and FOCUS (kindly donated by J Wands, MGH, Boston). Factor $\mathrm{V}$ was chosen as it is of major prognostic importance in fulminant hepatic failure.

Methods: Intracellular protein synthesis was assessed by incorporation of tritiated amino acids by cells cultured in the presence of normal or liver failure plasma from either humans, or rabbits after thioacetamide induced hepatitis. Levels of Factor $\mathrm{V}$ were measured under the same conditions with an ELISA.

Results: Thioacetamide $(600 \mathrm{mg} / \mathrm{Kg}$ bw.) resulted $38 \mathrm{~h}$ later in AST levels $>1000 \mathrm{IU} /$, and bilirubin of $28.9 \pm 18.5$ cf. $5.5 \pm 1.3 \mathrm{~g} / \mathrm{L}$ in normal rabbits $(x \pm S D)$. Normal human or rabbit plasma had no detrimental effect on total intracellular protein synthesis, nor in specific protein secretion, in any of the cell lines cultured. In contrast, both human and rabbit liver failure plasma reduced $3 \mathrm{H}$-amino acid incorporation by 30 $85 \%$ depending on the cell line. HuH 7 cells secreted high levels of Factor $\mathrm{V}$ in normal rabbit plasma (4200ng/mg cell protein) which was virtually abolished in liver failure plasma. Factor $\mathbf{V}$ levels in FOCUS cells were low but detectable and only decreased by $20 \%$ in liver failure plasma.

Conclusion: One of the most important liver functions, its protein synthetic capacity, is severely depressed by liver failure plasma. Bioartificial liver circuits need to address this function.
VITAMIN D AND MARKERS OF BONE FOKMATION IN PRIMARY BILIARY CIRRHOSIS John O'Donohue' ${ }^{1}$, Caje Moniz ${ }^{2}$, Yetunde Baoku', Roger Williams' ${ }^{1}$ Institute of Liver Studies ${ }^{1}$ and Dept of Clinical Biochemistry2, King's College Hospital, London SE5 9RS.

Introduction. Bone loss is a significant cause of morbidity in primary biliary cirrhosis (PBC), especially in the post-menopausal female. The relative contributions of increased bone resorption, decreased bone formation and defective mineralisation remain controversial. The aims of this study were to assess bone metabolism in PBC using novel assays for the biochemical markers of bone formation, serum osteocalcin $(\mathrm{Oc})$ and bone-specific alkaline phosphatase (BAP), and to investigate vitamin D nutrition. Patients. Fifty-five consecutive patients (51 female) with PBC were recruited, of whom 6 had Stage 4 disease, 13 stage 3, 17 stage 2, 13 stage 1 , and 6 indeterminate stage. Mean serum bilirubin was $20.7 \mu \mathrm{mol} / \mathrm{l}$ (SD 11.0). Mean serum albumin was $39.4 \mathrm{~g} / \mathrm{l}$ (SD 2.7). Thirteen patients were receiving cholestyramine, 9 cyclosporin A, 18 ursodeoxycholic acid, and 16 calcium supplements. Ten patients who were receiving either oestrogen or vitamin D therapy were excluded. Methods. Sera was frozen at $-20^{\circ} \mathrm{C}$. Intact serum $O c$ and BAP were each measured by ELISA (Medginex, Belgium and Metra, USA respectively) and a normal sex and age matched reference range was defined. Both assays had a coefficient of variation of less than $7 \%$. Other biochemical parameters were measured by standard chemistries, and vitamin $\mathrm{D}$ by competitive protein binding. Results. Mean serum $O c$ was $17.5 \mathrm{ng} / \mathrm{ml}$ (range 4.8-52.2ng/ml, SD 9.4) which did not differ significantly from the reference range. Oc did not correlate with bilirubin, histological stage, serum vitamin D, total or bony alkaline phosphatase, or drug treatment. BAP was significantly elevated compared with controls (mean 44.1u/l, SD 21.4, p<0.001) but correlated only with total alkaline phosphatase $(R=0.87)$. Serum Vitamin $D$ was significantly lower in the cholestyramine-treated group (mean $10.7 \mathrm{ng} / \mathrm{ml}$, SD 5.7 vs mean $19.3 \mathrm{ng} / \mathrm{ml}$, SD 8.9 in the rest, $P<0.0005$, normal reference range $10-42 \mathrm{ng} / \mathrm{ml})$. Serum calcium was normal in both groups. Discussion. Serum Oc, a sensitive marker of bone formation, is not increased, even in those patients with low serum vitamin $D$; this data favours the theory of 'low-turnover osteoporosis' in PBC. The use of BAP as a marker of bone formation in cholestatic patients may be limited by cross-reactivity with liver iso-enzymes. Low serum vitamin $D$ levels are strongly associated with cholestyramine therapy, and vitamin D (and calcium) supplements are advisable in this setting. 
Interferon (IFN) vs interferon + tauro-ursodeoxycholic acid (tUDCA) for treatment of chronic active hepatitic C (CAH-C): a multicentre randomized trial.

MG Pigozzi, R Sorbara, A Reggiani, GP Lorini, C Valsecchi, G Viviani, M DeTavonatti, A Rotondi, L Bettini, P Tebaldi, A Lanzini.

Coordinating Centre:Medicine 1, Spedali Civili. 25100 Brescia. Italy.

UDCA has been reported to reduce serum transaminases in CAH-C (Hepatology 1994; 20: 558), and to be useful as adjuvant therapy in non responders to IFN therapy (Gastroenterology 1994; 104: A941).

The aim of our study was to compare the efficacy on liver enzymes, viraemia and liver histology of lymphoblastoid IFN (3MU/m2 body surface area, 3 times per week) $+\mathrm{t}$-UDCA (10 mg/kg/day) with that of IFN alone given for 1 year. 115 patients have been randomized to IFN + t-UDCA $(n=57)$ or to IFN alone $(n=58)$. We report here results on liver enzymes in the first 64 patients completing 6 month treatment. Serum alanine aminotransferase (ALT) and gammaglutamiyl transpeptidase (GGT) activities are expressed as multiple of upper limit of normal range (uln). Patients with ALT $=<1$ uln following 6 months treatment are defined as responders.

Serum ALT decreased significantly from $4.5+0.6$ to $1.1+0.1$ (mean $\pm S E M, p<0.001)$, and from $3.0 \pm 0.2$ to $0.9 \pm 0.1 \quad(p<0.001)$ during IFN alone $(n=36)$ and IFN+ $t-U D C A(n=28)$ respectively, but responders during IFN+t-UDCA $(n=28)$ compared with 21 during IFN alone $(n=36, N S)$. ALT values at 6 months were lower for patients with pretreatment GGT $<1$ uln than for those with GGT $>1$ uln $(0.6 \pm 0.1$ vs $1.4 \pm 0.1$ respectively, $p<0.002)$, and for patients with pretreatment body mass index (BMI) $<25$ than for those with BMI $>$ $25(0.8 \pm 0.1$ vs $1.2 \pm 0.2$ respectively, NS). Responders were 28 and 12 among patients with pretreatment $G G T<1(n=35)$ and $>1 \quad(n=29$, $\mathrm{p}<0.015)$; and were 28 and 12 among patients with BMI $<25 \quad(\mathrm{n}=39)$ and $>25(n=25, p=0.055)$ respectively.

We conclude that on treatment response is similar during IFN+tUDCA and IFN alone in CAH-C; and that GGT and BMI are good predictors of biochemical response to IFN treatment. on treatment values were similar for the 2 regimens. There were 19

\section{AMYLQIDOSIS AND THE LIVER}

L. B. Lovat, M. R. Persey, S. Madhoo, M. B. Pepys, P. N. Hawkins (introduced by H. J. F. Hodgson)

Immunological Medicine Unit, Royal Postgraduate Medical School, Hammersmith Hospital, Du Cane Road, London W12

Systemic amyloidosis is a progressive multi-organ disease that is often fatal. Clinical features are non-specific and the diagnosis is frequently delayed. The previous necessity for histology to confirm the presence of amyloid made in vivo study of the distribution, extent and natural history of amyloid difficult. These problems have been surmounted by the development of quantitative scintigraphy using ${ }^{123} \mathrm{I}$-labelled serum amyloid $\mathrm{P}$ component (SAP), a normal plasma protein that binds specifically to all types of amyloid fibril. We report here the significance of hepatic involvement in 400 patients with amyloidosis.

1200 scans using ${ }^{123} \mathrm{I}$-SAP were performed in 400 patients with amyloidosis and 200 disease controls. The diagnostic accuracy of scans for hepatic amyloid in a series of 52 patients examined histologically or at autopsy was $98 \%$. Hepatic amyloidosis was identified by scanning in $19 / 115(16 \%)$ of patients with AA amyloidosis and 71/144 (49\%) with AL type. The liver was involved in most patients with hereditary nonneuropathic systemic amyloidosis but in no patient with familial amyloid polyneuropathy (FAP). Hepatic amyloid was usually unsuspected clinically and was always accompanied by amyloid in other organs. Alkaline phosphatase was only elevated in $11 \%$ of affected patients, and was elevated in $13 \%$ of amyloid patients without liver involvement. Serum bilirubin and clotting profiles were abnormal in only $3 \%$.

Serial SAP scans showed that hepatic amyloid progressed at different rates in different patients. Encouragingly, following treatment of the underlying disorder, hepatic amyloid often regressed substantially. Endstage liver failure was not seen but spontaneous hepatic rupture was treated successfully by emergency liver transplantation in one case. Elective liver transplantation as "surgical gene therapy" is now the treatment of choice in FAP, consistently halting disease progression.

\section{Liver (clinical) T106-T111}

COMBINATION URSODEOXYCHOLIC ACID AND IMMUNOSUPPRESIVE THERAPY FOR THE TREATMENT OF PRIMARY BILIARY CIRRHOSIS AG Lim. FHJ. Wolfhagen*, A Verma, RP. Jazrawi. HR. van Buuren*, JH. Levy, TC Northfield and SW. Schalm*. Dept of Medicine, St George's Hospital Medical School, London. UK and *Dept of Internal Medicine II, University Hospital Dijkzigt. Rotterdam, the Netherlands*

Ursodeoxycholic acid (UDCA) is currently the medical treatment of choice for primary biliary cirrhosis (PBC). As both cholestatic and immune mediated damage are likely to be important in the aetiology of PBC, a combination of UDCA and immunosuppressive agents may be more effective than UDCA alone. Our aim was to assess the effects of a combination of UDCA and low dose azathioprine and prednisone on immunological and biochemical markers in PBC. 24 patients with primary biliary cirrhosis received ursodeoxycholic acid (10 mg/kg/day) for 12 months and were then randomized in a double blind fashion to receive in addition either combination treatment with prednisone $(30 \mathrm{mg} /$ day first month, $20 \mathrm{mg} /$ day second month, $10 \mathrm{mg} /$ day maintenance) and azathioprine (50mg/day), or matching placebos. Immunological markers examined consisted of serum levels of IgM. soluble interleukin-2 receptor (sIL-2R) and soluble intercellular adhesion molecule-1 (sICAM-1). sIL-2R is marker of T-cell activation and sICAM- 1 has been used as a marker of disease activity in a variety of immune diseases. Biochemical markers consisted of serum liver function tests. At baseline, sICAM-1 correlated with histological stage. bilirubin. AST and ALT. During the first 12 months, UDCA therapy resulted in improvements in IgM $(p<0.0001)$ and sICAM-1 $(p<0.0004)$ but not in sIL-2R. Alkaline phosphatase (ALP), aspartate transaminase (AST) and alanine transaminase (ALT) also improved significantly (all $\mathrm{p}<0.0001$ ). The addition of azathioprine and prednisone for 6 months resulted in a further reduction of sICAM-1 levels by a median of $25 \%$, while remaining stable in the placebo group $(p<0.01)$. This was accompanied by improvements in ALP $(p<0.005)$, AST $(p<0.005)$ and $\operatorname{IgM}(\mathrm{p}<0.01)$ but not in IL-2R. We conclude that SICAM-1 reflects disease severity in PBC. Addition of low dose prednisone and azathioprine to UDCA further improves liver function tests and reduces levels of sICAM-1. The present study provides justification for larger, long term studies to determine the clinical value of combining UDCA with immunosuppressive therapy in the treatment of primary biliary cirrhosis, particularly with regard to disease progression.
T108

\section{ASSOCIATION BETWEEN CHRONIC HEPATITIS C VIRUS (HCV) INFECTION AND HEPATOCELLULAR CARCINOMA (HCC) IN A SCOTTISH POPULATION.}

GH Haydon*, LM Jarvis\#, IAD Bouchier*, P Simmonds\#, PC Hayes*. Dept. of Medicine* and Medical Microbiology\#, University of Edinburgh, Edinburgh.

Although Chronic HCV infection is believed to be important worldwide in the pathogenesis of HCC, its importance in the U.K. is unknown.

Methods: 114 cases of histologically proven HCC, diagnosed between 1985 and 1994 were examined to identify the aetiology of the HCC. Serum samples were tested serologically for markers of hepatitis B and C infection. Samples positive for HCV antibody were polymorphism analysis of PCR-amplified fragments of the $5^{\prime}$ noncoding region of HCV c-DNA

Results: Chronic HCV infection was the major risk factor identified ( 24 out of $114 ; 21 \%$ ). The mean age of the patients was $69.2+/-11.4$ years ( $21 \mathrm{male}) .20$ out of $24(83 \%)$ of the serologically positive patients had viral RNA in their serum. HCV genotype lb was predominant ( 16 out of 20 patients; $80 \%$ ); genotype 4 was present in three patients and genotype 5 in one. Co-carcinogenic factors to HCV seropositivity were documented in four patients (two had chronic HBV infection and two consumed excessive amounts of alcohol). Cirrhosis preceeded HCC in 20 out of 24 (83\%) of these patients. The time from $\mathrm{HCV}$ transmission to development of carcinoma ranged from 10 to 50 years (mean $32+/-11.6$ years). The likely mode of HCV transmission was a blood transfusion in 15 cases, sporadic in 8 cases and intravenous drug usage in 1 case.

Conclusions: There is a strong association between chronic HCV infection, cirrhosis and hepatocarcinogenesis in this Scottish population. The study supports the role of specific genotypes, paticularly $1 \mathrm{~b}$ and the relatively uncommon genotype 4 in the pathogenesis of HCC, as both are over represented in this HCC population. genotyped after RNA extraction and restriction fragment length 
II I'IO HEPATIC "P MAGNETIC RESONANCE SPICTROSCOPY: A PROGNOSTIC MARKER IN PATIENTS WITH PRTMARY BHINRY CIRRHOSIS?

R.J.jalan, J.Sargentoni, D.J.Bryant, G.A.Contts, J.D.Bell, LJ.COx. *K.Rolles, *A.K.Burroughs, S.D.Taylor-Robimson. R.E.Steiner MR Unit, Hammersmith Hospital and *Royal Free Hospital, London.

Aims To assess in vino hepatic 31 phosphorus magnetic resonance spectroscopy

$(3 ! P, M R S)$ as a prognostic marker in patients with $\mathrm{PBC}$ in relationship to the current clinical methods of assessment.

Patricuts and Methods Twenty-three patients with PBC of varying functional severiti and 16 matched healthy volunteors were studied using in vivo ${ }^{31} \mathrm{P}$ MRS. Spectra were acquired using a $1.5 \mathrm{~T}$ spectroscopy system. Peak area ratios of phosphomonoesters (PME), inorganic phosphate ( $\mathrm{Pi}$ ), phosphodiesters (P') ' and miclentide tri-phosphate (NTP) were calculated using NMR10 spectral processing program. Pugh score, Christensen prognostic index and $R$ vaine according to the Mayo model were calculated from the clinical data

Results Results are sunmarised in the Tables below

\begin{tabular}{|c|c|c|}
\hline Speriral variable & PBC & Controls \\
\hline$P: I^{\prime} \quad I T P^{2}$ & $1.37( \pm 0.4)$ & $0.89( \pm 0.6)$ \\
\hline$P i$ i $T^{P i l}$ & $1.4( \pm 1.1)$ & $0.97( \pm 1.6)$ \\
\hline $\mathrm{pH}$ & $7.5( \pm 0.2)$ & $7.47( \pm 1.2)$ \\
\hline$P \backslash I E \cdot P_{i}^{a}$ & $1.5( \pm 0.9)$ & $1.2( \pm 1.1)$ \\
\hline
\end{tabular}

$1.5( \pm 0.9)$ $1.2( \pm 1.1)$

Cri elations with the different prognostic models are summarised below

\begin{tabular}{|c|c|c|c|c|}
\hline Mndel & PME/Pi & pH & Pi/NTP & PMT/NTP \\
\hline Vivc model & $r=0.47, p<0.05$ & $r=0.6, p<0.01$ & NS & NS \\
\hline Christensen & $\tau=0.64, p<0.01$ & NS & $r=0.5, p<0.03$ & NS \\
\hline Puish Score & $r=0.45, p<0.05$ & $r=0.5, p<0.03$ & NS & NS \\
\hline
\end{tabular}

Conclusions This study shows that $\mathrm{PME} / \mathrm{Pi}$ ratio obtained from ${ }^{31} \mathrm{P}$ MRS co:Tclates well with all three of the commonly used models of prognosis in paiisints with PBC. A longitudinal study involving larger number of patients is undervay to confirm these observations and elucidate the biochemical mcchanisms underlying this phenomenon.
DISEASE SEVERITY IN CHRONIC HEPATITIS C VIRUS INFECTION IS RELATED TO MODE OF TRANSMISSION. GH Haydon, LM Jarvis, KJ Simpson, IAD Bouchier, P Simmonds, PC Hayes. Departments of Medicine and Microbiology, University of Edinburgh, Edinburgh.

Chronic infection with the hepatitis C virus (HCV) may lead to hepatic cirrhosis and to hepatocellular carcinoma (HCC). It is unclear which patients will develop severe disease.

Methods: 61 consecutive cases of HCV infection, presenting for diagnostic laparoscopy and liver biopsy were examined to identify risk factors for serious hepatic pathology (hepatic cirrhosis or HCC). Data on mode of transmission of the virus, the likely duration of infection, and histology at liver biopsy were recorded. Serum from each patient was examined for HCV genotype after RNA extraction and restriction fragment length polymorphism analysis of PCRamplified fragments of the 5 ' non-coding region of HCV c-DNA.

Results: Of the 61 patients, 26 (43\%; mean age 35+/-5 years) were infected following the recreational use of intravenous drugs; 11 (18\%; mean age $43+/-12$ years) had received a transfusion with $\mathrm{HCV}$ infected blood and 24 (39\%; mean age $53+/-11.5$ years) had no identifiable risk factors for infection. There was no significant difference in duration of HCV infection betweeen the drug using (median; 15 years) and transfusion cohorts (median; 8 years). There was no significant difference in the distribution of genotypes amongst the three subpopulations. However, a significantly larger proportion of the transfusion cohort had severe liver disease $(7 ; 67 \%)$ as compared with the drug using $(3 ; 12 \%)$ and sporadic $(5 ; 21 \%)$ cohorts $(\mathrm{p}<0.01)$.

Conclusions: In this population with chronic HCV infection, cirrhosis of the liver or HCC was seen in a significantly larger proportion of the cohort who had received a transfusion with infected blood despite a similar duration of infection to intravenous drug users. It is interesting to speculate that these patients received a higher initial viral load relative to other cohorts, which was asssociated with a more rapid progression of liver disease.
POOR PROGNOSIS AND LIMITED THERAPEUTIC OPTIONS IN PATIENTS WITH BUDD-CHIARI SYNDROME AND PORTAL VENOUS SYSTEM THROMBOSIS A.E.A.MAHMOUD \& E ELLAS.

The Liver \& Hepatobiliary Unit, Queen Elizabeth Hospital, Birmingham, UK.

INTRODUCTION: Therapeutic options in Budd-Chiari Syndrome (BCS) are highly dependent on the site and extent of hepatic vein thrombosis. The aim of this study was to evaluate the effect of additional portal venous system thrombosis on the clinical presentation, treatment and outcome in patients with BCS. PATIENTS \& METHODS; Clinical notes of 51 patients with BCS admitted to our centre were evaluated. We identified 13 patients (25\%) with BCS and portal venous system thrombosis. 10 patients were female and 3 male with a median age at presentation of 40 years (range 31-60). RESULTS; An underlying haematological aetiology was identified in 9 patients. Only 6 patients $(46 \%)$ were on warfarin before referral to our centre. In addition to hepatic vein thrombosis 7 patients had portal vein thrombosis (PVT), 3 had PVT, splenic vein(SV) and superior mesenteric vein (SMV) thrombosis and 3 had either SV, SMV or IVC thrombosis. The presentation was acute in 3 patients, subacute in 6 and chronic in 4 with a high incidence of history of encephalopathy $(9 / 13=70 \%)$. Treatment included liver transplantation (4), mesoatrial shunt (1), splenectomy and devascularisation of lower oesophagus (1), balloon dilatation of hepatic veins (2). 5 patients were treated medically as all other options were considered too risky or technically impossible. 9/13 patients $\mathbf{7 0 \% )}$ died either after surgery or before any treatment could be instituted (median survival 3 months range 1 week to 12 years),compared to $14 / 38(37 \%)$ in patients with isolated hepatic veins thrombosis ( median survival 1.5 years, range 3 months to 16 years) - CONCLUSION: Patients with BCS and portal venous system thrombosis constitute a unique group with limited therapeutic options and poor prognosis. The importance of early recognition and anticoagulation of patients with BCS is emphasized.

\section{Pancreas T112-T119}

T112

SERUM CARBOHYDRATE-DEFICIENT TRANSFERRIN REMAINS A RELIABLE MARKER OF HIGH ALCOHOL INTAKE IN ACUTE ABDOMINAL INFLAMMATORY CONDITIONS.

SK C Toh, C D Johnson. University Surgical Unit, Southampton General Hospital, Southampton SO16 6YD

Carbohydrate-deficient transferrin (CDT) is known to be a very reliable marker for alcohol abuse. Aim: To evaluate the sensitivity and specificity of serum CDT and gamma-glutamyl transferase (GGT) in detecting high alcohol intake in surgical patients admitted with acute pancreatitis (ap) $(n=12)$ and acute non-pancreatitis abdominal inflammatory conditions (aa) $(n=20)$ and patients with alcoholic (ald) $(n=12)$ and non-alcoholic (nald) $(n=17)$ chronic liver disease. Patients and Methods: 61 patients gave informed consent to enter the study (33 men, 45-76yr, median 65yr). A standardised questionnaire on drinking habits was completed by the patient and checked with a close relative. Blood samples were drawn to assay CDT and GGT. The serum CDT was determined using the $C D$ Tect kit (Kabi-Pharmacia). Results: 5/12 ap and 6/12 ald patients drank $>50 \mathrm{~g}$ alcohol/day for at least 1 week. Using cut-off points of serum CDT of $20 \mathrm{U} /$ (men) and 26U// (women), the accuracy of CDT in detecting high alcohol intake in each group were as follows:

\begin{tabular}{|l|l|l|l|l|l|}
\hline (\%) & All & ap & ald & ap+aa & ald+nald \\
\hline SENSITIVITY & 73 & 80 & 100 & 80 & 100 \\
\hline SPECIFICITY & 98 & 100 & 100 & 95 & 97 \\
\hline
\end{tabular}

GGT was sensitive ( $98 \%$ ) but had poor specificity $(50 \%)$. There was a highly significant correlation between CDT and alcohol intake (Spearman correlation, $p<0.0001$ ) in men. No such correlation was found with GGT. Conclusion: CDT is superior to GGT in detecting high alcohol intake, and remains reliable even in acute abdominal inflammatory disorders. 
GABEXATE MESILATE (FOY(O) IN THE PREVENTION OF PANCREATIC DAMAGE SECONDARY TO ENDOSCOPIC MANOEUVRES ON VATER'S PAPILLA. RESULTS OF AN ITALIAN RANDOMIZED DOUBLE- BLIND MULTICENTRE TRIAL.

L.Frulloni. G. Cavallini. A. Tittobcllo and the "Gruppo Italiano Gabesato Endoscopia Digestiva" (GRIGED). Italy:

Endoscopic retrograde cholangio-pancreatography (ERCP) and endoscopic sphinctcrotomy (ES) arc invasive manoeunres associated with an increase in pancreatic cnaymes in scrum in a substantial proportion of cases (up to 70\%). In addition. the clinical onset of acutc pancreatitis (AP) occurs in varying percentages of paticnts ( 1 to $11 \%$ ). In view of the large number of subjects submitted to these manocurres. effective pharmacological prevention of the scrum anylase clevation and/or AP after ERCP and/or ES would be an important goal. Scieral experimental studies in animals have demonstrated the efficacy of proteasc inhibitors in improving the histological picture and in reducing the mortality of AP induced by different procedures. This efficacy was maximal when the drug was administered prophylactically. Gabevate mesilate (FOY) is a synthetic protcase inhibitor endowed with a potent inhibitory action against a broad spectrum of pancreatic enrymes. The aim of this randomised double-blind multicentre trial was thus to craiuate the efficacy of FOY in the prevention of serum amslase clevation and AP in the course of ERCP and/or ES. A total of 424 paticnts ( 190 males. 234 females: mean age 60.4 years; range 19-96) were recruited in 17 Italian centres. Or these. 237 were submitted to ERCP and 187 to ES with or without ERCP. 213 patients were treated with FOY by continuous intravenous infusion at a dosc of $1 \mathrm{~g}$ starting $3(0-9) \mathrm{min}$ before execution of the cndoscopic manocuvrc and continuing up to $12 \mathrm{~h}$ after it, while 211 patients were trcated with placcbo according to the same procedure. The two treatment groups wcre well matched for scx. age. type of endoscopic manoeurre. BMI and endoscopy indications. Mean scrum amylase and lipase levels (assayed at baseline and at $4,8.12$ and $24 \mathrm{~h}$ ) were found to be increased compared to baseline in both groups. but the rise was significantly less in the FOY group than in the patients on placebo $(\mathrm{P}<0.05)$. Pain symptoms were experienced in 12 patients $(5.6 \%)$ in the FOY group as against 29 paticnts in the placebo group $(14 \%)(P<0.02)$. Onset of AP (at least a 5-fold increase in enzymes above the normal limits associated with abdominal pain) was observed in 5 patients $(2.4 \%)$ in the FOY group and in 16 patients $(7.6 \%)$ in the placebo group $(P<0.01)$. Conclusions: the results of the study provide evidence of the efficacy of FOY in reducing acute pancreatic damagc induced by ERCP and/or ES.
ABERRANT HLA-DR TISSUE EXPRESSION AND ACTIVATED LYMPHOCYTE RESPONSE IN DIFFERENT TYPES OF CHRONIC PANCREATITIS.

P Bovo, F Merigo, L Frulloni, D Sgarbi, M Filippini, B Vaona, V Di Francesco, G Talamini, L Rigo, MP Brunori, M Tebaldi, PC Farris, P Pederzoli*and G Cavallini. Gastroenterology Unit, *Surgical Dept., University of Verona, Verona, Italy.

It has been recently suggested that chronic pancreatitis could be pathogenically attributable to an obliterating primary inflammatory fibrosis of the main end/or secondary pancreatic ducts. Aberrant ductal HLA-DR expression, promoting lymphocyte periductal infiltration then fibrosis, could be an early pathogenetic factor in development of the disease. The aim of the study was to assess the aberrant HLA-DR expression and lymphocyte infiltration in pancreatic specimens from 6 normal pancreases and from 19 chronic pancreatitis patients, all but one with calcifications, submitted to pancreatico-jejunostomy, according to the following breakdown: 10 patients with primary chronic calcifying-calcific pancreatitis (CCP) (8 M, 2 F; mean age 45.8 \pm 9.1 yrs; alcohol intake 116.2 \pm 32.9 g/day); 5 patients with primary chronic hereditary pancreatitis (CHP) $(2 \mathrm{M}, 3 \mathrm{~F}$; mean age 17.8.9.3; tectotallers); 4 patients with chronic obstructive pancreatitis (COP) (2M 2 F- mean age $42.2 \pm 10.7 \mathrm{yrs}$; alcohol intake $67.5 \pm 47.2 \mathrm{~g} /$ day). Pancreatic tissue sections were stained by direct immunofluorescence (biotin-avidin system), and monoclonal antibodies against the B and T-lymphocyte populations and the non-polymorphic region of the HLA-DR molecules were used

\begin{tabular}{|c|c|c|c|c|}
\hline Greape (n) & & CCP (10) & CHP (5) & $\operatorname{COP}(4)$ \\
\hline \multirow[t]{3}{*}{$\%$ of ducts HILA positive } & $0 \%$ & 2 & 2 & 1 \\
\hline & $<50 \%$ & 1 & 0 & 0 \\
\hline & $>50 \%$ & 7 & 3 & 3 \\
\hline \multirow[t]{3}{*}{ HLA-DR reactivity } & - & 2 & 2 & 1 \\
\hline & t & 6 & 0 & 3 \\
\hline & + & 2 & 3 & 0 \\
\hline \multirow[t]{3}{*}{ Periductal lymp. infiltration } & $t$ & 0 & 1 & 0 \\
\hline & + & 2 & 1 & 1 \\
\hline & H & 3 & 1 & 0 \\
\hline
\end{tabular}

Results: In normal no reactivity of HLA-DR expression nor lymphocyte infiltration were observed. A large percentage of CCP, CHP and COP showed a high frequency of HLA-DR expression. However CCP and CHP showed the highest reactivity of HLA-DR expression and the major periductal lympho-cyte infiltration. In conclusion these results suggest a possible primary (auto) immunonologic pathogenetic mechanism in CCP and CHP but not COP.

\section{AMYLASE AND LIPASE LEVELS IN THE DIAGNOSIS OF ACUTE PANCREATITIS.}

P.J. Treacy, J.A.R. Williams, R. Bais. Introduced By M.W.R. Read. Hepato-Biliary and Pancreatic Surgical Unit, The Royal Adelaide Hospital, Adelaide, South Australia, 5000, AUSTRALIA.

The diagnosis of acute pancreatitis rests heavily on a raised serum amylase. In this study patients were prospectively categorized from clinical, laboratory, radiological, operative and autopsy data, but without knowledge of pancreatic enzyme levels, into either acute pancreatitis (51 patients), disease controls (35 patients), or exclusions (indeterminate: 189; diseases other than pancreatitis that produce elevated amylase: 53). Serum and urinary amylase (total and pancreatic isoenzyme) plus serum lipase were measured at days 1 to 3 following presentation. To evaluate diagnostic performance of each enzyme, receiver operating characteristic (ROC) curves were generated and analysed with specificity $>80 \%$. Sensitivity and specificity were determined at the arbitrary diagnostic threshold of three times the upper reference value.

Day 1 serum lipase gave the greatest diagnostic accuracy (area under ROC curve). Diagnostic accuracy was not increased by either urinary amylase/creatinine ration nor the combination of lipase and amylase. For a diagnosis at day 2 or day 3, no one enzyme tested was significantly superior to any other in terms of diagnostic accuracy, or area under ROC curve.

$\begin{array}{ccccc}\begin{array}{c}\text { Enzyme } \\ \text { (day 1) }\end{array} & \begin{array}{c}\text { ROC } \\ \text { Area }\end{array} & \begin{array}{c}\text { Diagnostic } \\ \text { Threshold }\end{array} & \text { Sensitivity } & \text { Specificity } \\ \text { Serum Lipase } & 0.128 & 694 & 49 \% & 97 \% \\ \text { Total Amylase } & 0.104^{*} & 355 & 28 \% & 97 \% \\ \text { Panc. Amylase } & 0.107^{*} & 266 & 35 \% & 97 \% \\ \text { Urine Amylase } & 0.108 & 1719 & 32 \% & 97 \%\end{array}$

$* \mathrm{P}<0.05$, vs day 1 lipase

We recommend serum lipase for diagnosis of acute pancreatitis. Although highly specific when elevated, pancreatic enzymes have low sensitivity. The use of amylase isoenzymes adds little to diagnostic accuracy.
T116

INVESTIGATION OF MICRONUTRIENT ANTIOXIDANT STATUS AS A POTENTIAL DETERMINANT OF SUSCEPTIBILITY TO CHRONIC PANCREATITIS AMONG ALCOHOLICS AT SOWETO. Schofield D1, Ally $R^{2}$, Segal $I^{2}$, Turner S1, Braganza JM'. 'Royal Infirmary, Manchester, UK; ${ }^{2}$ Baragwanath Hospital, Johannesburg, RSA

It is unclear why only some Sowetan Africans suffer from calcific chronic pancreatitis (CCP) when alcoholism is rife in this community. We have investigated whether differences in micronutrient antioxidant status may underlie this paradox. Fasting samples of plasma, serum or urine were obtained from three African groups: 15 controls; 21 healthy alcoholics; and 14 consecutive patients with alcoholic CCP. Results: Comparisons by Wilcoxon's Rank Sum Test (two-tailed): data as medians (ranges); " $p<0.05$, " $p$ $<0.01$ vs controls; ${ }^{+} p<0.05,+p<0.01$ CCP vs alcoholics.

\begin{tabular}{|c|c|c|c|}
\hline & Controls & Alcoholics & CCP \\
\hline Plasma vitamin C & 17.6 & $9.7^{\star}$ & $10.8^{*}$ \\
\hline$(\mu \mathrm{mo} / \mathrm{h})$ & $(4.5-75.5)$ & $(1.7-39.2)$ & $(4.5-18.7)$ \\
\hline Serum selenium & 1.33 & 0.95 & $0.85^{-1}$ \\
\hline (umol/n) & $(1.03-1.61)$ & $(0.53-1.57)$ & $(0.39-1.23)$ \\
\hline Plasma total & 6.24 & $4.01+$ & $2.19+$ \\
\hline glutathione ( $\mu \mathrm{mol} / \mathrm{l})$ & $(4.81-10.55)$ & $(1.70-7.88)$ & $(0.44-6.05)$ \\
\hline $\begin{array}{l}\text { Urinary inorganic } \\
\text { sulphate: creatinine }\end{array}$ & $\begin{array}{l}1.02 \\
(0.62-1.90)\end{array}$ & $\begin{array}{l}1.08 \\
(0.25-2.16)\end{array}$ & $\begin{array}{l}0.64 \\
(0.01-1.34)\end{array}$ \\
\hline & & & \\
\hline
\end{tabular}

Comments: Asymptomatic alcoholics at Soweto have levels of vitamin $C$ and selenium as low as in patients with $C C P$, suggesting equally poor dietary intakes. However, the decrement in plasma glutathione was less in the alcoholics than in patients with CCP and, also in contrast, their inorganic sulphate level was preserved. Since these two substances are both involved in detoxification reactions, the results suggest that sustained exposure to other environmental chemicals may be the factor which cascades the changes towards CCP among antioxidant-deficient alcoholics at Soweto. 
PANCREAS DIVISUM IN ACUTE PANCREATITIS: CURIOUS COINCIDENCE Gastroenterology Royal Berkshire and Battle Hospitals NHS Trust Reading RH1 5AN

The possibility that pancreas divisum (PD) confers an increased risk of an association. We have therefore analysed 2083 consecutive ERCP's performed in a District General Hospital over an eleven year period (1984-1994)

A pancreatogram was obtained in 963 cases and PD noted in 47 (4.8\%). Pancreatography was achieved in $130 / 150(86.7 \%)$ patients referred for investigation of acute pancreatitis and PD was found in 17 (31.3\% of all cases of PD) The prevalence of $\mathrm{PD}$ among patients with acute pancreatitis was significantly greater $(p<0.001)$ compared to those cases referred for investigation of other conditions (usually suspected or who had both a cholangiogram and pancreatogram, ERCP diagnoses were: gallstones ( $n=51[39 \%])$, alcohol induced pancreatitis $(n=32$ $[25 \%])$, carcinoma $(n=3[2 \%]), \operatorname{PD}(n=17[13 \%])$ or no abnormality detected $(n=27[21 \%])$

A pancreatogram was not obtained in 20 patients either due to the demonstration of CBD stones $(n=6)$, or multiple gallstones $(n=6)$ where persistent attempts at pancreatography were not made, or failure to cannulate $(n=8)$. PD was therefore present in 17 of $44(38.6 \%)$ cases where no widely accepted cause of acute pancreatitis could be demonstrated

These findings strongly support the contention that pancreas divisum is not merely a harmless anatomical variant but is an anomaly conferring a significantly increased risk of acute pancreatitis. OR COVERT CULPRIT?

A.V. Thillainavagam and A.S. Mee Department of acute pancreatitis remains controversial. Referral bias has been a major criticism of surveys from tertiary referral centres which have shown such actual biliary obstruction). Of the 130 patients with acute pancreatitis

\section{EVALUATION OF THE ROLE OF BRANCHED CHAN AMINO ACIDS IN THE TREATMENT OF PROTEIN MALNUTRITION IN INFANTS WITH LIVER DISEASE. Protheroe S, Jones R, Kelly DA.}

Liver Unit, Children's Hospital, Birmingham, B16 BET.

It has been suggested that BCAA enriched feeds have advantages over standard formulas in improving nutritional status in children with end-stage liver disease. Furthur studies are needed to establish which groups may benefit from these relatively expensive sources of protein before they are widely adopted. We aimed to evaluate BCAA in infancy, a period of rapid somatic growth where adoption of rational nutritional intervention is critical.

METHODS.A 12 week randomised double-blind cross-over trial to compare BCAA-enriched feed with matched standard protein feed in infants with compensated liver disease.Clinical, nutritional and biochemical data is assessed at entry, cross-over and at the end of the study. RESULTS

Anthropometry. $n=24$, Mean age 4.14 months (+/-1.98)

\begin{tabular}{lllcc}
\hline & Entry & End & Standard & BCAA foed. \\
\hline & \multicolumn{2}{c}{ Mean z score } & \multicolumn{2}{c}{ Change in z score } \\
Weight & -0.82 & -0.13 & +0.3 & +0.36 \\
Length & & $p<0.01$ & & $p=0.29$ \\
Fat & -1.03 & -0.37 & +0.35 & +0.19 \\
& & $p<0.01$ & & $p=0.11$ \\
Muscle & -0.65 & +0.61 & +0.72 & +0.44 \\
& & $p<0.01$ & & $p=0.15$ \\
& -0.99 & +0.49 & +0.62 & +0.86 \\
& & $p<0.01$ & & $p=0.14$
\end{tabular}

Growth failure was marked despite compensated liver disease Short-term nutritional intervention significantly improved all anthropometric parameters. There was no significant difference in growth during the BCAA period in this group of infants compared to the standard feed. There appeared to be improved muscle growth on the BCAA feed,perhaps because of leucine enhancing muscle protein synthesis. The relative concentrations of BCAA may be important and are deserving of furthur study, but we cannot currently justify the use of this BCAA supplement in these infants 1.Garlick PJ, Grant I. Biochem J. 1988;254:579-84.

\section{Acid-peptic disorders T120-T128}

T120

T118

MALNUTRITION, ESSENTIAL FATTY ACIDS DEFICIENCY (EFA) AND INTAKE THRESHOLD IN BILIARY ATRESIA? SV Beath ${ }^{1}$, TE Johnson 1 , DA Kelly' ${ }^{1}, \mathrm{KD}$ Willis ${ }^{2}$, INM Hooley ${ }^{2}$, SG Johnson', IW Booth' ${ }^{2}$. The Liver Unit ${ }^{1}$ and The Institute of Child Health ${ }^{2}$, The Children's Hospital, Birmingham UK.

Linoleic and linolenic (EFA) are essential precursors of complex structural lipids which are found in high concentrations in phospholipid membranes in red blood cell (RBC), photoreceptors and the brain. EFA's cannot be synthesised de novo by mammals, but as they are found abundantly in long chain fats of marine and plant oils, deficiency states are uncommon. However, children with fat malabsorption secondary to biliary atresia require dietary modifications to improve their nutritional state and could be at risk of EFA deficiency. Anthropometry and EFA status were studied 4 times in 18 weeks in four children who had varying net intakes of EFA. EFA status was determined by measuring the ratio of abnormal eicosatrienoic acid to arachidonic acid in RBC membranes by gas liquid chromatography (GLC). This ratio called the triene:tetrene ratio was $<0.1$ in 10 normal controls. The net intake of EFA was calculated from excretion of individual fatty acids determined by GLC of extracted faecal lipid.

Results

\begin{tabular}{ccccc} 
Subj & $\begin{array}{l}\text { EFA mg/k/d } \\
\text { net intake } \\
\text { range }\end{array}$ & $\begin{array}{l}\text { triene: } \\
\text { tetrene } \\
\text { range }\end{array}$ & $\begin{array}{l}\mathrm{mg} / \mathrm{k} / \mathrm{day} \\
\text { EFA intake } \\
\text { threshold }\end{array}$ & $\begin{array}{l}\text { wt. z } \\
\text { score }\end{array}$ \\
\hline 1 & $408-986$ & $0.1-0.42$ & 986 & -2.75 \\
2 & $310-559$ & $0.0-0.22$ & 310 & -1.23 \\
3 & $142-423$ & $0.0-0.13$ & 142 & -0.11 \\
4 & $269-999$ & $0.0-0.10$ & 269 & -0.94 \\
\hline
\end{tabular}

The threshold of EFA intake required to maintain a normal triene:tetrene ratio varied depending on the subjects' nutritional status. A correlation between poor nutritional status (weight $z$ score -2 or worse) and high net requirement for EFA was found $(r=-0.97 p=0.03)$, suggesting that in some subjects EFA was being diverted from biosyntheis to provide energy. A correlation between $\mathrm{Ht}$, midarm circumference and triceps skinfold and EFA threshold requirement was not found. Subjects with liver disease who require nutritional support are likely to need at least $1000 \mathrm{mg} / \mathrm{kg} / \mathrm{day}$ of EFA per day to avoid EFA deficiency.
UREA SOLUTION FOR DIRECT H. PYLORI TESTING

A Case of Premature Evaluation?

BATESON, M.C., BABORIE, A., BAKIR, A., BARNES, S. G WINN, G.

GENERAL HOSPITAL, BISHOP AUCKLAND, CO. DURHAM, UK.

Urease testing of gastric biopsies is probably the best technique for demonstrating active H.p. infection in endoscopy patients.

98 consecutive patients with intact stomachs and no relevant drug therapy for 2 months had 4 antral biopsies taken for CLO-test gel examination, culture histology, and microscopy with Giemsa stain. CLO-test gave $98 \%$ sensitivt and 898 specificity compared with microbiological culture. which is itself tedious and not consistently successful. Other tests performed even less well.

"One minute" unbuffered urea solution testing of gastric biopsies was proposed as a rapid cheap alternative which gives equivalent results to the CLO-test (ref.). 135 unselected patients had duplicate adjacent gastric antral biopsies taken for simultaenous CLO-test gel and urea solution testing. Results were as follows:-

\section{1 minute \\ 10 minutes \\ 20 minutes \\ 3 hours}

16 hours $\frac{\text { Both Positive }(n=64)}{\text { Urea Solution }}$

67 were negative by both techniques at $16 \mathrm{hr}$. Three patients were positive by urea solution at 3-16 $\mathrm{hr}$, but negative by urea gel at $16 \mathrm{hr}$. One was positive by CLO-test at $16 \mathrm{hr}$. but negative by urea solution. The total cost of each urea solution test was 30p. Each CLO-test slide cost $£ 2.13$.

CONCLUSION: Urease testing using home-made solution is as reliable and much cheaper than commercial gel test. However, it is not alway's rapid, and must be reviewed after 1 minute if not positive then. 
A COMPARISON OF FIVE COMMERCIAL SEROLOGICAL TESTS FOR HELICOBACTER PYLORI DETECTION.

P Nair, CAM McNulty*, BE Watson*, JS Uff, R Valori, Gloucester Public Health Laboratory.

Introduction: The gold standard diagnosis by histopathology and culture of Helicobacter pylori are invasive and both take several days. Numerous serological kits are now commercially available to provide cheaper and more rapid diagnosis. In this study we compare 1 latex and 4 ELISA kits (Pyloriset latex, Pyloriset EIA, Launch Premier H.pylori, Biorad GAP IgG \& Shield Diagnostic Helico-G).

Method: Dyspeptic patients aged $18 \mathrm{yr}$ and over attending Gloucester Royal Hospital for a routine endoscopy were considered for the study. The gold standard used was microscopy of H\&E and half Gram stained histological sections, culture on selective and non-selective medium and biopsy urease test.

Results: H.pylori was detected in 32 of 82 patients. The latex test was easy to perform but sensitivity was only $75 \%$. Biorad and Shield were $100 \%$ sensitive but had a specificity of $67 \%$. The Biorad had $10 \%$ of tests in the equivocal range. Pyloriset EIA and Launch were also very sensitive ( 94 \& 97\%) and good specificity (77\% \& $85 \%$ ). Six of 7 patients negative by the gold standard had a past history of ulceration or past proven $H$.pylori infection and antimicrobial therapy. If these were included as positives the specificity of all tests improved.

Conclusion: The Pyloriset latex kit had a good specificity but poor sensitivity compared with the other ELISA kits. The Launch Premier kit had the best overall results and was the easiest ELISA to perform, but is only qualitative and expensive. A quantitative result is obtained from Pyloriset EIA Biorad GAP and Shield Helico-G, which may be useful in long term follow-up after treatment.
POLYMERASE CHAIN REACTION (PCR) FOR DETECTION OF HELICOBACTER PYLORI DNA IN PATIENTS WITH H PYLORI INDUCED GASTRITIS SUGGESTS THAT DENTAL PLAQUE IS NOT A RESERVOIR.

MM Ozmen, AC Gough, CD Johnson

University Surgical Unit, Southampton General Hospital, Southampton, SO16 6YD, UK.

Though $\mathrm{H}$ pylori is an important factor for gastrointestinal disease possible routes of spread of infection remain to be elucidated. Little data is available on the prevalence of $\mathrm{H}$ pylori infection in the mouth. In order to confirm previous reports that dental plaque may harbour $\mathrm{H}$ pylori and act as a reservoir for re-infection of the stomach we studied 26 patients $(18 \mathrm{~m}, 8 \mathrm{f}$, median (range) age 50 (28-71 years) with $\mathrm{H}$ pylori gastritis.

Dental plaque was collected before endoscopy by scraping.During endoscopy the gastric antrum was biopsied for histology and nestedPCR. Nested-PCR was performed on total DNA extracts from both dental plaque and stomach biopsies. Primers directed at, and specific for, a final product of $372 \mathrm{bp}$ from $\mathrm{H}$ pylori urease were used.

24 of 26 antral biopsy samples $(92.3 \%)$ were positive by both histology and PCR. None of the dental plaque sampled were positive by PCR.

Our results with $\mathrm{H}$ pylori-specific nested-PCR suggest that dental plaque is not a reservoir for $\mathrm{H}$ pylori infection and so is unlikely to be an important source of transmission and reinfection. Differences from previous findings may be due to variations in sample collection, or to contamination of the oral cavity by biopsy forceps, endoscope or refluxed gastric juice.
AUDIT OF A SPECIALISED HELICOBACTER PYLORI TREATMENT CLINIC. AF Goddard, CJ Hawkey \& RC Spiller. Division of Gastroenterology, University Hospital, Nottingham.

Eradication of Helicobacter pylori infection is indicated in the management of duodenal ulcer. The effectiveness of most eradication regimes outside the context of a clinical trial is unknown. For the past two years patients in our hospital with proven $H$. pylori infection have been referred to a specialist treatment clinic.

Methods We have audited the results of eradication treatment from April 1994 to March 1995. All patients had endoscopic evidence of duodenal ulcer or duodenitis. Treatment was issued as follows: De-Nol 1 tab ads, tetracycline $500 \mathrm{mg}$ ads and metronidazole $400 \mathrm{mg}$ tds for 2 weeks (BTT) from April until October; omeprazole 20mg, clarithromycin $250 \mathrm{mg}$ and metronidazole $400 \mathrm{mg}$ all bd for 1 week (OCM) from October until January; and OCM with tinidazole $500 \mathrm{mg}$ instead of metronidazole (OCT) from January until March. No treaments were given within the context of a clinical trial. Eradication was assessed by ${ }^{14} \mathrm{C}$-urea breath test. Side effects were recorded as present if the patient stopped medication or they disrupted normal activities. All visits were supervised by one doctor (AFG). Besults

\begin{tabular}{lcccc} 
& BII & OCM & OCT & Total \\
\cline { 3 - 5 }$n$ & 91 & 63 & 50 & 204 \\
MF & $67 / 24$ & $42 / 21$ & $35 / 15$ & $144 / 60$ \\
Mean age & 49 & 53 & 53 & 51.2 \\
Eradication & $81 \%$ & $90 \%$ & $86 \%$ & $84 \%$ \\
Side effects & $12 \%$ & $1.5 \%^{*}$ & $0 \%^{*}$ & $6 \%$ \\
Compliance & $97 \%$ & $99 \%$ & $100 \%$ & $98 \%$
\end{tabular}

Cenclusions $H$. pylori eradication rates of $81-90 \%$ can be achieved outside of clinical trials using accepted regimes. Of these OCM and OCT are better tolerated than BTT.

CLARITHROMYCIN (C) OR AMOXICILLIN (A) DUAL AND TRIPLE THERAPIES IN H. PYLORI (HP) ERADICATION: A META-ANALYSIS. Chiba N, Wilkinson JM, Hunt RH. Division of Gastroenterology, McMaster University, Hamilton, Canada.

Clarithromycin is the most effective single agent for Hp eradication. Clarithromycin or amoxicillin with omeprazole $(\mathrm{O})$ are widely used dual therapies. Adding a nitroimidazole $(N)$, metronidazole $(M)$ or tinidazole (T) may improve eradication rate. However, confusion exists as to the relative efficacy of these regimens.

METHODS: Searched: Medline and recursive review of all papers to April 1995 and meeting abstracts 1993-95: AGA, ACG, BSG, UEGW, WCG and annual European Hp Meetings. Included: Adult prospective studies, providing per protocol data of number eradicated per number treated when assessed 4 weeks post eradication therapy. Excluded: Multiple publications. Data: Pooled as the mean percent eradication independent of drug dose and treatment duration.

RESULTS: 6372 evaluable patients. OC is significantly better than OA with no overlap of $95 \% \mathrm{CI}$. OC gives more consistent results than $\mathrm{OA}$ as reflected by the smaller SD. Treatment time was 2 wks in $21 / 29(O C)$ and $70 / 90 \mathrm{OA}$ arms. OCN is significantly better than OAN $(6.8 \%$ difference, $95 \%$ CI $1.0-12.6 \%, p<0.05$ ) with more consistent results (smaller SD narrower $95 \% \mathrm{CI}$ ). $13 / 18$ arms with $O C N$ used 1 wk regimens vs $4 / 18$ for OAN and 1/8 for OCA. OCA is effective but less consistent than OCN

Regimen(n) n patients mean\%erad \pm SD $95 \% \mathrm{CI}$

$\begin{array}{lccc}\text { OC(29) } & 1098 & 70.8 \pm 12.3 & 66.1-75.5 \%\end{array}$

$\begin{array}{llll}O A(90) & 3242 & 61.3 \pm 20.7 & 57.0-65.7 \%\end{array}$

$\begin{array}{llll}\text { OCN(18) } & 842 & 90.9 \pm 6.0 & 88.0-93.9 \%\end{array}$

$\begin{array}{llll}\text { OAN(18) } & 931 & 84.1 \pm 10.5 & \mathbf{7 8 . 7}-89.5 \%\end{array}$

$\begin{array}{llll}\text { OCA(8) } & 259 & 85.3 \pm 13.0 & \mathbf{7 4 . 5}-96.2 \%\end{array}$

CONCLUSIONS: Omeprazole/clarithromycin achieves higher and more consistent $H$. pylori eradication than omeprazole/amoxicillin $(71 \%$ vs $61 \%$ ) with 2 week therapy. Omeprazole/clarithromycin/nitroimidazole eradicates over $90 \%$, mostly with 1 week therapy. Omeprazole/ clarithromycin/nitroimidazole is more effective and more consistent than omeprazole/amoxicillin/nitroimidazole. 
OUTCOME OF HELICOBACTER PYLORI ERADICATION IN OMEPRAZOLE, CLARITHROMYCIN AND TINIDAZOLE TREATMENT FAILURES. P Moayyedi, DS Tompkins*, S Barrowclough, J Pearson, ATR Axon. Centre for Digestive Diseases, Leeds General Infirmary, *Dept. Public Health Medicine, Leeds

Introduction: Omeprazole $20 \mathrm{mg}$ bd/od, clarithromycin $250 \mathrm{mg}$ bd and tinidazole $500 \mathrm{mg}$ bd for one week (OCT) is an effective treatment for $\mathrm{H}$ pylori. Treatment fails in approximately $10 \%$ of patients and it is unclear whether further therapy is effective and what is the most appropriate eradication regimen to prescribe.

Methods: A retrospective notes survey of $H$ pylori positive patients treated with OCT was performed. Infection was confirmed by histology, rapid urease test and ${ }^{13} \mathrm{Carbon}$ Urea Breath Test $\left({ }^{13} \mathrm{C}\right.$-UBT) and eradication of infection was evaluated by ${ }^{13} \mathrm{C}$-UBT at least four weeks after completion of therapy. Treatment failures were prescribed either bismuth salts $120 \mathrm{mg}$ qds, tetracycline $500 \mathrm{mg}$ qds and metronidazole $400 \mathrm{mg}$ tds (BTM), omeprazole $20 \mathrm{mg}$ bd and amoxycillin $1 \mathrm{~g}$ bd $(\mathrm{OA}), \mathrm{OA}$ with clarithromycin $500 \mathrm{mg}$ bd $(\mathrm{OAC})$ or omeprazole $20 \mathrm{mg}$ bd and clarithromycin $500 \mathrm{mg}$ tds $(\mathrm{OC})$ all for two weeks.

Results: Treatment with OCT failed in 38/334 (11\%) patients. 11 of these cases either refused further treatment $(n=4)$ or were lost to follow-up $(n=7)$. Overall $12 / 27(44 \%)$ cases had successful second line treatment. $6 / 9$ had successful treatment with BTM ( $H$ pylori sensitive to metronidazole in one patient, others unknown). $5 / 9$ had successful treatment with OA ( $H$ pylori resistant to clarithromycin and metronidazole in 5 cases). 1/7 had successful treatment with OAC $(H$ pylori sensitive to clarithromycin in the successfully treated case, resistant in 3 cases). $0 / 2$ had successful treatment with $O C$ (both $H$ pylori strains sensitive to clarithromycin). Combining the $\mathrm{OA}$ and BTM results gives an eradication rate of $11 / 18(61 \%)$ whilst $O A C$ and OC give a $1 / 9(11 \%)$ eradication rate $(p=0.04$ Fisher's exact test).

Conclusions: BTM and OA are effective second line $H$ pylori eradication regimens for OCT treatment failures. Regimens containing clarithromycin are less successful.

\section{ACUTE AND CHRONIC EFFECT OF LANSOPRAZOLE AND} OMEPRAZOLE IN RELATION TO FOOD INTAKE.

$R-\sqrt{M}$ Brummer $B J$ Geerling, $R W$ Stockbrügger. Dept. Gastroenterology - University Hospital Maastricht. PO Box 5800, NL6202 AZ Maastricht, The Netherlands.

We investigated whether the timing of food intake influences inhibition of gastric acid secretion by proton pump inhibitors (PPIs).

Sixteen healthy volunteers (M:8, F:8, age:20-42 yrs) participated in a placebo-controlled, randomized, double blind, multiple cross-over study. Treatment arms: Placebo (PL), Omeprazole 20mg after breakfast (OA), Lansoprazole $30 \mathrm{mg}$ after brealfast (LA) and Lansoprazole $30 \mathrm{mg}$ before breakfast (LB). Treatment period: 15 days; wash out period: 20 days. On days 1 and 15 , an ambulant 24 -hr intragastric $\mathrm{pH}$ recording was performed. Results were expressed as mèdian 24-hr $\mathrm{pH}$ (med-pH) and percentage of 24 -hr $\mathrm{pH}$ above $3(\% \mathrm{pH}>3)$.Values are given with $25 \%$ to $75 \%$ quartile ranges. On day 1 , during $\mathrm{LB}$, med-pH / \%pH $>3$ (3.0, range 2.4-3.7 / 49.9\%, range 41.0-60.1) differed significantly from PL (1.1, range $1.0-1.4 / 14.1 \%$, range 8.6-18.9) $(p<0.05)$. On day $1, L A$ and $O A$ did not significantly differ from PL.

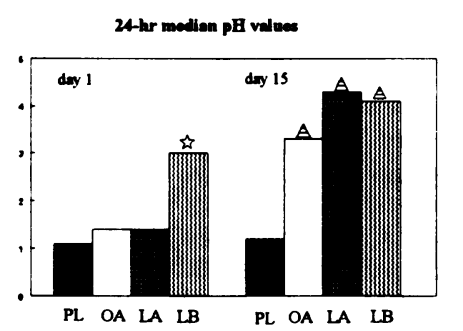

On day $15, \mathrm{LB}$ and LA were equally effective in reducing gastric acid secretion [med-pH 4.1, range 3.34.5/ 4.3, range 2.7-5.1 (n.s.)] and did not differ from OA (med-pH 3.3, range 1.7-4.5).

At start of oral therapy, PPIs should be given before meals. In chronic use the relationship of drug intake to meals is not important.

\section{PEPTIC ULCER AND GASTRITIS IN URAEMIA}

KY Ho, JY Kang, KG Yeoh, R Guan, E Lee*, CC Tan*, WC Lye*, SO Leong*, Divisions of Gastroenterology and Nephrology*, Department of Medicine, National University of Singapore, Singapore

The metabolic derangements in uraemia may have adverse effects on the gastroduodenal mucosa. This study aimed to examine the prevalence and clinical characteristics of endoscopic gastritis, histological gastritis and peptic ulcer in patients with end-stage renal failure requiring maintenance dialysis treatment.

257 consecutive patients presenting for maintenance dialysis treatment had gastroduodenoscopy performed by a single investigator. Findings were compared to those of 294 consecutive patients with non-ulcer dyspepsia (NUD). Clinical characteristics of 38 uraemic patients with peptic ulcer (13 presented with symptoms) were compared with those of 69 consecutive non-uraemic patients with peptic ulcer. Uraemic patients $(n=38)$ with no history of recent exposure to antibacterial treatment had gastric biopsies taken for assessment of histological gastritis and Helicobacter pylori (HP) status. Histological findings were compared with those of 32 age and sex-matched non-uraemic patients with NUD and 18 healthy volunteers.

Endoscopic gastroduodenitis was more common in uraemic patients (73\%) compared to patients with NUD $(43 \%, p<0.0001)$. It was not affected by the duration of dialysis treatment. The types of ulcers in the uraemic patients (gastric $34 \%$, duodenal $68 \%$, gastric and duodenal $3 \%$ ) and non-uraemic patients $(32 \%, 64 \%, 4 \%$ respectively) were comparable. $46 \%$ of duodenal ulcers in uraemic patients occurred in the second part of the duodenum compared to $6 \%$ in the non-uraemic group $(\mathrm{p}<0.01)$. Multiple ulcers were more frequent in uraemic patients $(34 \%$ vs $12 \%, p<0.01$ ). Amongst patients with ulcers who had not received antibiotics recently, HP was positive in $21 \%$ uraemics and $64 \%$ nonuraemics $(p<0.05)$. The prevalence of histological antral gastritis and HP in uraemic patients $(42 \%, 18 \%)$ were similar to those in healthy volunteers $(22 \%, 11 \%)$ but lower than in patients with NUD $(66 \%$ $\mathrm{p}<0.05 ; 44 \%, \mathrm{p}<0.05$ )

Compared to subjects with NUD, uraemic patients had more endoscopic gastroduodenitis but a lower prevalence of histological antral gastritis and HP. Peptic ulcers in uraemic patients were atypical in site, more often multiple and less often HP positive compared to non-uraemic patients. These differences may be due to the effects of uraemia on the gastroduodenal mucosa.
T128

CONTINUOUS TREATMENT OF PATIENTS WITH BARRETT'S OESOPHAGUS WITH OMEPRAZOLE $20 \mathrm{mg}$ DAILY OVER 3 YEARS.

TH labal, C S Neumann, M A Cox, J C Gearty, B T Cooper. Gastroenterology Unit, City Hospital, Birmingham, B18 7QH.

Barrett's oesophagus [BO] is a complication of gastro-oesophageal reflux [GOR]. As the metaplastic columnar epithelium in $\mathrm{BO}$ has malignant potential, an aim of treatment is to reduce GOR which could lead to regression of the Barrett's epithelium. Proton pump inhibitors are the most effective medical treatment for GOR and may offer an approach to regression. We have reported the results of treatment with omeprazole $20 \mathrm{mg}$ mane for 12.24 months in BO showing squamous island re-epitheliazation in about $54 \%$ of patients but without significant reduction in the length of the Barrett's segment. In this prospective open study, we report observations on some of these patients after 3 years treatment. 12 patients [3M; 9F] with BO, aged 50 - 84 years, have been treated continuously with omeprazole $20 \mathrm{mg}$ mane for 36 months. Patients were assessed endoscopically. Omeprazole controlled reflux symptoms in all patients, none of whom suffered any adverse event from the drug. The mean length [ \pm SD] of the BO segment before treatment with omeprazole was $7.41 \pm 2.19 \mathrm{~cm}$ whereas the mean length after 3 years treatment was not significantly different at $7.08 \pm 2.27 \mathrm{~cm} .5$ patients [42\%] had between 1 and 8 [mean 5] macroscopic squamous islands visible below the squamo-columnar junction. No patient had dysplasia at the onset of the study and none developed dysplasia or carcinoma during the course of the study. We conclude that omeprazole $20 \mathrm{mg}$ daily over 3 years does not cause significant shortening of the BO segment but a proportion of patients develop squamous islands within the BO segment. However that proportion does not increase with time on omeprazole. 
MULTIPLE CHEMOKINE GENES ARE EXPRESSED IN LIVER TISSUE FROM PATIENTS WITH CHRONIC HEPATITIS C INFECTION

KJ SIMPSON, DJ HARRISON, LM JARVIS AND PC HAYES. Dept of Medicine, Pathology and Virology, University of Edinburgh, Edinburgh. UK

Chemokines are small molecular weight cytokines with chemoattractant properties. Although some subset specificity has been reported at least 7 chemokines attract lymphocytes in vitro. The aim of this study was to determine which of these chemokines were expressed in liver tissue in chronic hepatitis $\mathrm{C}(\mathrm{HCV})$ infection

METHODS. Reverse transcriptase polymerase chain reaction techniques were used to determine expression of interleukin 8 (IL8), monocyte chemotactic protein (MCP) 1, MCP 3 , interferon inducible protein (IP) 10 , macrophage inflammatory protein (MIP) $1 \alpha$, MIPI $\beta$ and RANTES in hepatic CDNA from 15 patients with chronic HCV infection. In addition 5 patients were studied in the last month of a 6 month course of interferon $\alpha$ (IFN). Hepatic histology was assesed using a modified Knodell system and HCV genotype determined by RFLP digestion of PCR amplified fragments of the 5' noncoding region of of HCV cDNA.

RESULTS. In the untreated group, MCP1 was expressed in 15/15 biopsies, IL8 14/15, MIP1 $\beta$ 11/15, IP10 9/15, MIP1 $\alpha$ 5/15, RANTES $3 / 15$ and MCP3 $0 / 15$. There was no association between any chemokine expressed and the degree of lobulitis, triaditis or presence of lymphoid aggregates or the HCV genotype. During IFN treatment, although all patients responded with a reduction in serum ALT and improved pathology, MCP1, MIP1 $\beta$ and IL8 expression was detected in all 5 patients, IP10 and MIP $1 \alpha 3 / 5$, RANTES $2 / 5$ and MCP3 0/5. All of these patients relapsed after IFN was stopped.

CONCLUSIONS. Multiple chemokine genes are expressed in the liver in patients with $\mathrm{HCV}$ infection and interferon therapy has no effect. This may explain the high rate of relapse following IFN therapy. In addition specific therapy directed against a single chemokine is unlikely to be effective in patients with $\mathrm{HCV}$ infection in view of the redundant expression of chemokine genes observed in these patients.

THE ROLE OF PLASMA FACTORS IN THE ABNORMAL CALCIUM SIGNALLING OF PLATELETS FROM PATIENTS WITH CIRRHOSIS. Forrest EH, Dillon JF, Hayes PC. Liver Research Laboratories, Department of Medicine, Royal Infirmary, Lauriston Place, Edinburgh.

Platelets from patients with cirrhosis have abnormal lower basal cytosolic calcium concentrations $\left(\left[\mathrm{Ca}^{2+}\right]_{i}\right)$ than controls. As well as impairing platelet aggregation, these changes may be reflected in vascular smooth muscle accounting for the peripheral vasodilatation typical of these patients. The aim of this study was to assess the role of plasma-bourne factors in the abnormal $\left[\mathrm{Ca}^{2+}\right]$, of platelets.

Platelets were obtained from 26 control subjects and 11 patients with cirrhosis. After washing the platelets were incubated in their own fresh plasma. Platelets from controls were then incubated in fresh plasma and plasma which had been previously stored at -20 degrees $C$ from 26 patients with cirrhosis. The incubation was for $\mathbf{4 5}$ mins in the presence of FURA-2AM to allow subsequent calculation of $\left[\mathrm{Ca}^{2+}\right]_{i}$ by single wavelength spectrofluorimetery.

Control platelets in their own plasma had higher basal $\left[\mathrm{Ca}^{2+}\right]$, than patient platelets in their own plasma (128.4 +/- 7.8 cf $95.7+/-10.0 \mathrm{nmol} / / ; p=0.02$ ). After incubation in fresh patient plasma, control platelet $\left[\mathrm{Ca}^{2+}\right]$; fell to $93.0+/-9.3$ nmol/l $(p=0.005)$. Previously frozen patient plasma did not have this effect $(117.6+/-2.1 \mathrm{nmol} / /)$.

Conclusions: Fresh plasma from patients with cirrhosis contains a factor which causes a fall in platelet $\left[\mathrm{Ca}^{2+}\right]$. However when previously frozen plasma is used this effect upon $\left[\mathrm{Ca}^{2+}\right]_{i}$ is absent. This gives an insight into the cellular mechanisms underlying the defect in platelet aggregation noted amongst these patients, and also their disturbed vascular tone.
SELECTIVE DEPLETION OF KUPFFER CEUS IN RESTING RAT LIVER INITLATES DNA SYNTHESIS IN HEPATOCYTES. RA Boulton, M R Alison*, M Golding*, D Vesey, C Selden, HJF Hodgson. Gastroenterolgy Unit and Dept. of Histopathology* Royal Postgraduate Medical School, London W12 ONN UK.

Background. In normal liver hepatocytes are quiescent cells capable of responding to injury by a rapid surge of DNA synthesis and division. Processes determining quiescence and maintaining replication are complex and appear to involve paracrine interactions between liver cell subpopulations. Kupffer cells lie close to hepatocytes in the hepatic sinusoids where they secrete a number of biologically active molecules many of which have been implicated in liver growth (e.g. TGF $\beta$, TNFa, IL-1). In this experiment we demonstrate that selective depletion of Kupffer cells from resting rat liver results in an increase in DNA synthesis in hepatocytes. Methods. Kupffer cells were depleted by liposome-mediated delivery of dichloromethylene bisphosphonate ( $\left.\mathrm{Cl}_{2} \mathrm{MBP}\right)$, controls received PBS. Rats were sacrificed at 36,48 or 60 hours. Bromodeoxyuridine (BrdUrd) was given $1 \mathrm{~h}$ prior to sacrifice to identify S-phase cells. Liver tissue was immunostained using anti-ED2 (to detect Kupffer cells) and anti-BrdUrd antibodies. Sections were scored by assessing 2,000 hepatocyte nuclei in random fields at a final magnification of $\times 400$.

Results. Kupffer cells were absent in $\mathrm{Cl}_{2} \mathrm{MBP}$ - treated animals as judged by ED2 staining, normal numbers were seen in controls. Hepatocyte morphology was similar in both groups. BrdUrd labelling in the $\mathrm{Cl}_{2} \mathrm{MBP}$-treated Kupffer cell depleted animals was significantly higher than in PBS treated animals, and mitotic figures were also more frequent ( 5.5 vs 0.3 at $60 \mathrm{~h} p<0.05$ ) BrdUrd labelling (Mean \pm SD per 1,000 hepatocyte nuclei)

\begin{tabular}{|c|c|c|c|}
\hline & $36 \mathrm{~h}$ & $48 \mathrm{~h}$ & $60 \mathrm{~h}$ \\
\hline $\begin{array}{l}\text { PBS } \\
\mathrm{Cl}_{2} \mathrm{MBP}\end{array}$ & $\begin{array}{r}1.17 \pm 0.98 \\
7.17 \pm 2.86\end{array}$ & $\begin{array}{l}0.66 \pm 0.60 \\
7.26 \pm 6.69^{*}\end{array}$ & $\begin{array}{r}2.50 \pm 1.95 \\
19.5 \pm 10.73^{*}\end{array}$ \\
\hline
\end{tabular}

Conclusion. Kupffer cell depletion appears to initiate recruitment of quiescent hepatocytes into the cell cycle. This indicates that there is a resting paracrine inhibitory tone.

Acknowledgement. Boehringer Mannheim $\mathrm{GmbH}$ for the gift of $\mathrm{Cl}_{2} \mathrm{MBP}$.
BILIARY MICROFLORA AND ITS RELATION TO BILIARY SEPSIS AFTER LIVER TRANSPLANTATION.

AEA Mahmoud, B Ferraz-Neto, D Mirza, E Rees*, T Elliot* and E Elias.

The Liver \& Hepatobiliary unit and Department of Microbiology*, Queen Elizabeth Hospital, Birmingham, UK.

INTRODUCTION: Biliary tract complications including infection remain an important cause of morbidity following liver transplantation. The aim of this study was to assess the spectrum of biliary microflora and its relation to biliary tract infections after liver transplantation.

METHODS: From January 1993 to March 1995, 298 adult liver transplants were performed in Birmingham. 117 patients had a T-tube inserted providing a port for bile collection. Microbiological data on these patients were reviewed and notes of 33 patients ( $28 \%$ ) with positive biliary cultures were evaluated.

RESULTS: 13/117 patients (11\%) had unequivocal clinical evidence of biliary sepsis with or without biliary leak (group I). $20 / 117$ patients $(17 \%)$ with positive bile culture had no definite evidence of biliary sepsis. In these patients bile was cultured at the time of investigation of unexplained fever and subsequently a cause for their fever was identified (group II). In group I bile cultures were positive on 39 occasions; Staphylococcus epidermidis (SE) 14, enterococcus species (ES) 13, diphteroid species (DS) 5, Pseudomonas aeruginosa (PA) 4, others 3 . In 7 patients the organisms isolated were sensitive only to Vancomycin (4 patients showed clinical improvement and 3 died). Organisms isolated in these patients were; SE 5, ES 4 and DS 1. In group II bile cultures were positive on $\mathbf{4 3}$ occasions. The organisms isolated were; SE 13, ES 8, DS 7, others 15.

CONCLUSION: These results suggest that $\mathbf{S}$. epidermidis, enterococcus species and diphteroid species are the commonest potential pathogens to colonize $\mathbf{T}$-tubes and cause biliary sepsis after liver transplantation. In patients with biliary sepsis blind antibiotic therapy should be directed to cover these organisms and Vancomycin should be considered as a first choice antibiotic. 
31P-ATP REGENERATION FOLLOWING STORAGE \& REPERFUSION OF THE DONOR PIG LIVER.

Chanqani, K.K., Fuller, B.J., 'Bell, J.D., 'Bryant, D.J., 'TaylorRobinson, S. \& Davidson, B.R.

Dept. Surgery, Royal Free Hospital London.

"NMR Unit Hammersmith Hospital, London.

Introduction - Liver transplantation over the past decade has proved to be extremely effective for the treatment of chronic liver diseased patients. However, improvements which can be made on the technique of liver preservation and storage must still be addressed. Most donor liver studies have been conducted on rats with very few clinically related animal models investigated. This study, therefore, has used the pig model to delineate the changes in ATP and the important glycolytic intermediate, 3-phosphoglycerate (3PG), which occur during donor liver storage and subsequent hypothermic reperfusion ( $\mathrm{HtR})$, by using ${ }^{31} \mathrm{P}$ magnetic resonance spectroscopy (MRS).

Methods - Wedge liver biopsies were removed from 5 Land Race pigs at sequential time points prior to and post liver harvest. At $2 \mathrm{~h}$ post harvest, the liver under went $\mathrm{HtR}$ with UW preservation fluid and sequential liver biopsies removed during the period of $\mathrm{HtR}(2 \mathrm{~h})$ and subsequent cessation of $\mathrm{HtR}$. All liver biopsies were freeze-clamped in liquid nitrogen and their perchlorate extracts analysed using a 11.7T MRS machine.

Results - ATP levels were seen to decrease significantly immediately following liver harvesting. At $15 \& 30 \mathrm{~min}$. harvesting, ATP levels fell by $54 \%(P<0.05) \& 87 \%(P<0.001)$, respectively. At $2 \mathrm{~h}$ post harvest there was no detectable ATP. Upon HtR ATP recovered to levels only $25 \%$ lower than pre harvest values. In contrast 3 PG showed an inverse relationship increasing by $900 \% \quad(\mathrm{P}<0.001) 45 \mathrm{~min}$ post harvest compared with pre-harvest levels. Upon HtR, 3PG levels reduced to $170 \%$ above pre-harvest levels.

Conclusions - This study has shown for the first time that ATP regeneration can be achieved following a period of HtR in the donor pig liver. It has also shown that by using ${ }^{31} \mathrm{P}-\mathrm{MRS}$ glycolytic intermediates such as 3PG can simultaneously be monitored. Using this technique it is possible to delineate the procedures of liver harvesting to improve the viability of stored donor livers.
THE IMPROVED RESULTS OF EMERGENCY ORTHOTOPIC LIVER TRANSPLANTATION FOR FULMINANT AND SUBACUTE HEPATIC FAILURE

DF Mirza, R Mohamed, BK Gunson, DJ Mutimer, AD Mayer, JAC Buckels, JM Neuberger, E Elias, P McMaster. The Liver Unit, Queen Elizabeth Hospital, Birmingham, UK.

Orthotopic liver transplantation (OLT) is the treatment of choice in selected patients with fulminant hepatic failure (FHF). Patients/Methods: From 1984 to Feb 1995,576 patients $(529$ adults, 47 paediatric) were admitted with FHF or subacute hepatic failure. Of these, 195 were listed for OLT, and 145 (115 adults - 71 females, median age 38 , range $16-65.5$ years; 30 paediatric - 17 females, median age 3.5 , range $0.2-15.9$ years) underwent emergency OLT. The diagnoses were NANB FHF $(n=72)$, subacute NANB $(n=19)$, paracetamol $(n=20)$, idiosyncratic drug reaction $(n=10)$, hepatitis A $(n=6)$, hepatitis $B(n=7)$, Wilson's disease $(n=6)$, others $(n=5)$. In 10 patients, liver function recovered before a graft could be found, and 40 patients died while on the emergency waiting list. Results: The median waiting period before a suitable donor organ became available was 1 day in both adult (range $0-14$ ) and paediatric (range $0-18$ ) recipients. These 145 patients underwent a total of 174 OLTs. There were 56 post OLT deaths due to: sepsis $(n=21)$, cerebral ( $n=14)$, pulmonary $(n=7)$,

haemorrhage $(n=7)$, rejection $(n=2)$, recurrent disease $(n=2)$, vascular $(n=2)$, and primary nonfunction $(n=1)$. The overali patient survival at 1 year for the entire series is $63 \%$, and for the patients transplanted since $1992 \quad(n=67)$ is $76 \%$ compared to $47 \%$ up to $1991 \quad(n=78) \quad(p=0.003$, Logrank). Conclusion: The standardisation of selection criteria, surgical techniques and perioperative management have resulted in this improved survival after OLT for fulminant and subacute hepatic failure.
AUTOIMMUNE HEPATITIS: APFLICATION OF INTERNATIONAL GROUP CRITERIA AND CLINICAL EXPERIENCE IN A SINGLE CENTRE. P Basumani, M Gordon, JCE Underwood*, $D$ Gleeson. Departments of Gastroenterology and Pathology*, Royal Hallamshire Hosfital, Sheffield S10 $2 \mathrm{JF}$

We have applied the International Group (IG) scoring system for diagriosis of Autoimmune Hefatitis (AIH) (Hepatology 1993 18:998-1004) to patients seen between 1971 and 1994 with a clinical diagnosis of AIH. 98 patients ( 10 men) met the IG criteria for AIH (47 definite, 51 probable). Mean age at onset was $53 \pm$ SD16 (range 7-77) years. 16 patients preserited with acute hepatitis, 9 with ascites and 3 with variceal bleeding. 37 patients had a past history or family history of autoimune disease. Hypergammaglobulingemia was present in 93 patients, antinuclear antibody $(\geqslant 1: 40)$ in 75 , anti smooth muscle antibody $(\geqslant 1: 20)$ in 42 and anti mitochondrial antibody in 8 . Of 78 patients tested for hepatitis $C, 2$ were positive. Of 92 patients who underwent liver biopsy, 84 had piecemeal necrosis, 17 had bridging necrosis. 10 had rosettes and 10 had a mainly plasma cell infiltrate. 2 patients had granulomas and 2 more developed granulomas on follow-up biopsy. 34 patients had cirrhosis and a further 30 had liver fibrosis. Of 81 fiatients treated with immunosupression, 76 had a complete and 2 a partial biochemical response by IG criteria. 45 patients had at least one relapse after treatment reduction or withdrawal. Over $85 \pm 66$ (range 6-276) months follow up 5 patients died from liver disease (4 liver failure, 1 hepatoma). all had presented with decompensated liver disease. 7 patients died from non-hepatic and 2 from unknown causes. Conclusions: No single feature confirms or excludes a diagnosis of AIH when defined by IG criteria. The outlook for treated disease is good.
Hypercoagulability in patients with Primary Biliary Cirrhosis (PBC) and Primary Sclerosing Cholangitis (PSC) evaluated by thromboelastography. Z Ben-Ari, M Panagou, D Patch, S Bates', E Osman, AK Burroughs.

Hepatobiliary and Liver Transplantation Unit, and 'Department of Anaesthesia, Royal Free Hospital, Pond Street, LONDON UK.

Patients with PBC and PSC survive variceal bleeding better than alcoholic cirthotics and have less bleeding at liver transplantation. We hypothesized that PBC and PSC patients may be hypercoagulable. As this is difficult to diagnose with routine laboratory tests, we used thromboelastography (TEG), which is a simple technique for evaluating whole blood clotting and fibrinolysis to establish if hypercoagulability was present, defined by TEG values greater than 2SD over controls: $r$ $<19 \mathrm{~mm}$ (this reflects plasma clotting factors), maximum amplitude (ma) $>60 \mathrm{~mm}$, and alpha angle $>43^{\circ}$ (this reflects platelets and fibrinogen levels). We evaluated 48 PBC and 21 PSC patients and 40 non-cholestatic cinthotic patients as a control group with TEG, full blood count, prothrombin time (PT), partial thromboplastin time (PTTK), fibrinogen, protein S, C, antit thrombin III levels and activated protein $C$ (APC) phenotype. Two or more TEG abnormalities indicating hypercoagulability were diagnosed in 14 of $48(29 \%)$ PBC and in 9 of 21 (43\%) PSC patients independent of cirrhosis, but only in 2 of $40(5 \%)$ of the control group, $p<0.03$ and $p<0.0002$ respectively. The 23 hypercoaguable patients had median values: shortened $\mathrm{r}$ of $12.0 \mathrm{~mm}(2.15)$, wide ma of $74 \mathrm{~mm}(61-87)$ and a wide angle $51^{\circ}(43-62)$. There was no correlation between the fibrinogen (which was normal or low in all patients) and platelets levels and the TEG parameters. There were no differences in protein $S, C$, antithrombin III levels between non and hypercoagulable groups. APC phenotype was normal in all patients who were hypercoagulable on TEG studied so far. This study shows that TEG can detected hypercoagulability in cirthotics which can not be detect by routine coagulation tests. This difference between biliary and parenchymal liver disease may have clinical implications (eg. haemostasis during bleeding, thrombosis post transplant) which need to be defined. In addition the reasons for hypercoazulability need to be explained by further study. 


\section{A DISTRICT GENERAL HOSPITAL'S EXPERIENCE OF PRIMARY SCLEROSING CHOLANGITIS. A REVIEW OF 13 CASES.}

J.Fletcher. M.J. Girundman (Chesterfield and .iorth Dertishire Royal Hosphal) March 1995

Betueen 1981 and 1094 thirteen patients were diagnosed at this hospital as having Primar. Sclerosing Cholangttis ( P.S.C.)

The mean age at diagnosis was 49 (26-74) with a male to female ratio of 9:4. Six patients presented with abnormal LFTs. four with jaundice, two with pruritus and one with cholangitis. At presentation two patients had hepatomegaly and a third had spider naevae and ascites but the remainder had no signs of liver disease. Diagnosis was confirmed by cholangiography in all 13 cases

Eight ( $61 \%$ ) had Ulcerative Colitis preceeding their P.S.C.by an average of 19 years. The tipical mild pan-coltus was found in 7 . There have been three colectomies; one for failure of medical treatment.one for severe displasia and one for Duke's C adenocarcinoma of the sigmoid colon

In December 1994 the average follow up period was 5 vears ( range 1-151 months). There were four deaths. Two died of cholangiocarcinoma which had been identified along with (a) 54 and another man died of non hepatic causes aged 77 . Before their deaths both men had stable liver function tests. In the remaining nine patients there has been no evidence of the development of currhosis or hepatic failure.

Apart from the two patients dving at presentation uith cholangiocarcinoma the remaining 11 patients had more 'benign disease. Their average period of follow up is 6 years from diagnosis at ERCP and $7 / 2$ vears from presentation. During this time 7 of these 11 patients have remained astmptomatic. Two suffered mild pruritus needing treatment and another two have been jaundiced intermittently in one case. Recurrant cholangitis has been a problem in 3 of these painentis o reciving courses of antibiotics from their G.P. and one requir hospital admissions. Repeat ERCP has not revealed stentable strictures.

The liver function tests are stable or improving in all but one patient whose alkaline phosphatase has risen from 95 to 193 ( N.R. 30-110) since 1989. The alkaline phosphatase is greater than 410 in 3 patients, less than 400 in 6 and normal in 2

Our experience leads us to conclude that if Cholangiocarcinoma is not found at presentation. P.S.C. mav result in a prolonged period ( currently up to 20 years, mean $71 / 2$ vears, in our study ) uithout disease progression, during which the patient enjoys good health
DOES OPEN ACCESS GASTROSCOPY INCREASE THE DETECTION RATE OF EARLY GASTRIC CANCER? RESULTS OF A 5 YEAR STUDY. Suvakovic Z, Bramble MG, Wilson C, Jones RA, Idle N, Ryott J.

Departments of Gastroenterology and Pathology, Middlesbrough General Hospital, Middlesbrough TS5 5AZ

A reported increase in the incidence of early gastric cancer (ECG) has been attributed to open access gastroscopy (OAG) without a detailed study of patients referred in this way. We have examined clinical details including age, sex, symptoms, general practitioner diagnosis and tumour staging (using the 1987 United International Tumour, Node Metastasis (TNM)

classification) of 39 patients diagnosed between 1989 and 1994 at OAG. The results were compared with those found in 142 patients diagnosed as having gastric cancer following clinic referral.

Results: The overall incidence of EGC was $4 \%$ with an additional $9 \%$ having stage I disease. Of 39 patients diagnosed following OAG nine had early or stage I disease compared to 15 of 142 patients diagnosed following clinic referral $\left(x^{2}=3.149 p>0.05\right)$. Although $M: F$ ratio, mean age and site of tumour growth were similar in both groups, the symptom profiles and general practitioner diagnosis differed significantly with only 20 (51\%) of the OAG group having worrying symptoms (dysphagia, anaemia or weight loss) compared to $120(85 \%)$ of patients referred through the outpatient clinic $\left(x^{2}=17.43 p<0.001\right)$. Gastric cancer was suspected in only six patients referred for OAG compared to 49 patients referred to a consultant $\left(x^{2}=4.42 p<0.05\right)$.

Conclusion: EGC remains a rare condition in our health district with only $13 \%$ of all patients having EGC or stage I disease. The trend towards more patients with earlier disease in the OAG group is explained by referral bias. Open access gastroscopy per se does not increase the detection rate of early gastric cancer.

\section{GI cancer T138-T146}

\section{OPEN ACCESS ENDOSCOPY FACILITATES EARLY DIAGNOSIS OF MALIGNANT AND PRE-MALIGNANT LESIONS OF THE STOMACH AND OESOPHAGUS.}

O` Hanlon DM, Karat D. Hayes N, Scott D*, Raimes S, Griffin SM. Depts of Surgical Gastroenterology and Pathology*, Newcastle General Hospital, Newcastle.

Open access endoscopy (OAE) is increasingly being viewed as an efficient and effective method for diagnosing upper GI pathology. obviating the need for clinic review. The greatest potential benefit of OAE is early diagnosis of malignant and in particular of pre-malignant lesions, and rapid institution of appropriate therapy and entry into controlled surveillance programmes when appropriate. This study prospectively evaluated our experience with OAE on 2000 consecutive referrals. All patients had proformas filled by their GPs giving patient details and complaints. These were reviewed by the surgeon and completed after endoscopy. Results see table.

\begin{tabular}{lcccc} 
Diagnosis & Number (\%) & mean (SEM) age & Age v benign & $\mathbf{m}: \mathbf{f}$ \\
\hline Carcinoma & $85(4.5)$ & $66.6(1.2)$ & $\mathrm{P}<0.0001$ & $1.8: 1$ \\
Oesophageal & $23(1.2)$ & $68.7(2.2)$ & & $1.9: 1$ \\
Gastric & $54(2.8)$ & $65.2(1.5)$ & & $1.8: 1$ \\
Barrett's & $54(2.8)$ & $60.6(2.0)$ & $\mathrm{P}=0.0001$ & $1.8: 1$ \\
CAG + int metapl & $179(9.4)$ & $56.4(0.9)$ & & $1.3: 1$ \\
Benign & $1401(73.6)$ & $53.2(0.4)$ & $\mathrm{P}<0.0001$ & $1.3: 1$ \\
Normal & $362(19)$ & $48.6(0.8)$ & $0.6: 1$ \\
Statistics: Mann Whitney U. Significance assumed at $\mathrm{P}<0.05$ level. &
\end{tabular}

Endoscopy was performed on 1902 patients and had a diagnostic yield of $81 \%$. Carcinoma was diagnosed in 85 and included 54 gastric cancers of which $10(18 \%)$ were early i.e. 1 in 190 endoscopies demonstrated early gastric cancer; 187 patients with potentially pre-malignant lesions were entered into surveillance programmes.

In conclusion this study supports the wider introduction of OAE for the diagnosis of pre-malignant lesions and for the early diagnosis of malignant lesions.
TOTAL N-NITROSO COMPOUND (TNNC) CONCENTRATION CORRELATES WITH INCREASING RISK OF GASTRIC

CANCER

Reed PI, Shen Z-Z, Johnston BJ and Hill MJ

Lady Sobell Gastrointestinal Unit, Wexham Park Hospital, Slough, Berks, SL2 4HL

Mean $\mathrm{pH}$, nitrite and TNNC concentration were measured in 116 fresh gastric juice samples obtained at endoscopy from various groups of gastrointestinal patients (Table)

\begin{tabular}{|l|l|l|c|c|}
\hline Patient Group & $\mathrm{n}$ & $\mathrm{pH}$ & $\begin{array}{l}\text { Nitrite } \mu \mathrm{mol} / / \\
(\mathrm{Mean} \pm \mathrm{SE})\end{array}$ & $\begin{array}{c}\text { TNNC } \mu \mathrm{mol} / \\
(\mathrm{Mean} \pm \mathrm{SE})\end{array}$ \\
\hline Normal & 44 & 2.9 & $3.9 \pm 1.6$ & $1.3 \pm 0.2$ \\
\hline DU & 16 & 1.9 & $0.6 \pm 0.6$ & $1.2 \pm 0.5$ \\
\hline GU & 10 & 3.0 & $9.6 \pm 9.6$ & $1.8 \pm 0.7$ \\
\hline V\&P & 11 & 4.1 & $28.4 \pm 15.0^{*}$ & $1.7 \pm 0.4$ \\
\hline Gastric atrophy & 14 & 5.1 & $29.4 \pm 7.5^{*}$ & $3.0 \pm 0.8^{*}$ \\
\hline Partial g'ectomy & 9 & 7.5 & $81.4 \pm 30.1^{*}$ & $3.9 \pm 0.7^{*}$ \\
\hline PA & 9 & 8.2 & $55.0 \pm 5.9^{*}$ & $3.3 \pm 1.0^{*}$ \\
\hline Gastric cancer & 3 & 7.7 & $25.0 \pm 9.5^{*}$ & $7.1 \pm 0.7^{*}$ \\
\hline
\end{tabular}

As expected there was a good correlation between mean gastric juice $\mathrm{pH}$ in the patient groups and the mean nitrite and mean TNNC concentrations. The increasing mean TNNC concentrations were directly related to the increasing gastric cancer risk in the patient groups from DU and GU (low risk) through gastric atrophy and PA (high risk) to gastric cancer.

The data are consistent with the hypothesis that TNNC are, at least in part, responsible for the progression from chronic atrophic gastritis through dysplasia to gastric cancer. 
PRE-OPERATIVE HEPATIC ARTERIAL LIPIODOL FOR THE DETECTION OF HEPATOCELLULAR CANCERS IN CIRRHOTIC EXPLANT LIVERS

S Bhattacharya, AP Dhillon", K Savage", AK Burroughs". K Rolles, BR Davidson

Departments of Surgery, Histopathology" and Medicine" Royal Free Hospital and Medical School, London NW3 206

Early hepatocellular cancers may be found in patients undergoing orthotopic liver transplantation (OLT) for end stage liver disease. This study has determined whether preoperative intra-arterial administration of Lipiodol can improve the detection of small HCC's in cirrhotic explant livers.

50 elective OLT patients were administered $10 \mathrm{mls}$ of Lipiodol at routine hepatic angiography. Following OLT the explant liver was processed routinely') $(1 \mathrm{~cm}$ slicing of the liver with biopsy of any focal nodules). For this study a single slice of each liver with no focal nodules was preserved and all slices of those with focal nodules. A soft tissue X-ray was performed of each slice and areas of Lipiodol uptake or increased soft tissue density were biopsied as were all raised nodules, those $>1 \mathrm{~cm}$ or with altered colour. Biopsies were fixed in formalin and stained with haematoxylin and eosin.

There were 5 exclusions due to protocol violations. Routine assessment of 45 livers revealed $17 \mathrm{HCC}^{\prime} \mathrm{s}$ in 6 livers. The study protocol revealed $55 \mathrm{HCC}$ 's of 103 nodules biopsied. Lipiodol retention on soft tissue $X$-ray was found in 25 of the HCC's $(45 \%)$. Additional cancers were all in the 6 patients in whom HCC was diagnosed by routine processing.

Routine processing of explant cirrhotic livers underestimates the number of primary cancers but seperates cancer containing from non cancerous livers. (1) Demetris A : Path Ann 1987; 22 (2) : 347-386
GLUTATHIONE - S- TRANSFERASE (GST THETA 1) GENOTYPES AND SUSCEPTIBILITY TO GASTRIC AND COLORECTAL CARCINOMA

M.Deakin, J.B.Elder, C.Hendrickse, K.Brannigan, A.A.Fryer, R.C.Strange N.Staffordshire Hospital, Stoke on Trent.

Accumulating evidence indicates susceptibility to several cancers is mediated by genetically determined differences in the effectiveness of detoxification of potential carcinogens. The theta class GSTT1 locus is relevant in this context as homozygosity for the null allele is common. GSTT1 utilises various potential carcinogens including the alkyl halides.

GSTT1 null and expression genotypes were identified by PCR on leukocyte DNA in 114 patients with gastric carcinoma and 211 patients with colorectal carcinoma. The frequency of gene expression was compared with that in 509 local controls.

The table shows the frequency of GSTT1 in cases and controls.

\begin{tabular}{l|ccc}
\multirow{2}{*}{$\begin{array}{l}\text { GSTT1 } \\
\text { pos }\end{array}$} & Controls & \multicolumn{1}{c}{$\begin{array}{c}\text { Colorectal } \\
\text { Carcinoma }\end{array}$} \\
\cline { 2 - 4 } $\begin{array}{l}\text { GSTT1 } \\
\text { null }\end{array}$ & $415(81.5 \%)$ & $148(70.1 \%)$ & $93(81.6 \%)$ \\
& $94(18.5 \%)$ & $63(29.9 \%)$ & $21(18.4 \%)$ \\
& $n=509$ & $n=211$ & $n=114$
\end{tabular}

Frequencies of GSTT1 genotypes in gastric carcinoma and controls were not significantly different.

In colorectal carcinoma cases the frequency of GSTT1 was significantly increased compared with controls $\left(X^{2}=10.69\right.$; $\mathrm{p}=0.0011$; odds ratio $=1.88,95 \%$ CI $1.28,2.77$ ). There was no significant relationship with either gender, Dukes stage, age at presentation or tumour differentiation.
TUMOUR RESPONSE TO REGIONAL CHEMOTHERAPY DEPENDS UPON TUMOUR VASCULARITY IN COLORECTAL LIVER METASTASES

D.Burke, S.Kaur, C.Fordy, S.Earlam, T.G.Allen-Mersh. Dept of Academic Surgery, Chelsea \& Westminster Hospital; London.

Vascularity of colorectal liver metastases (CLM) might influence extent of tumour drug uptake, and hence response. We have assessed the effect of tumour vascularity on response in 21 CLM patients undergoing regional Floxuridine chemotherapy. This included 11 patients who were 5-FU resistant after initial respnse to systemic 5-FU based chemotherapy. Patients underwent CLM biopsy at time of regional chemotherapy catheter insertion. Vessels were stained immunohistochemically with the anti-endothelial antibody JC70. Vessel count and volume were assessed by a graticule counting method at $\times 200$ magnification. Response to 4 months of chemotherapy was assessed by CT scan

\begin{tabular}{|c|c|c|c|}
\hline & & $\begin{array}{l}\text { vessel count } \\
\text { (no./mm } / \mathrm{mm}^{2} \\
\text { (median, igr) }\end{array}$ & $\begin{array}{l}\text { vessel volume } \\
\text { (\% of tissue) } \\
\text { (median, igr) }\end{array}$ \\
\hline & $\begin{array}{l}\text { response } \\
(n=6)\end{array}$ & $\begin{array}{c}37.3^{*} \\
(253-519)\end{array}$ & $\begin{array}{c}7.0^{* *} \\
(44-7.9)\end{array}$ \\
\hline $\begin{array}{l}\text { no previous } \\
\text { chemotherapy }\end{array}$ & $\begin{array}{l}(\mathrm{n}=6) \\
\text { non-response } \\
(\mathrm{n}=4)\end{array}$ & $\begin{array}{c}(25.3-51.9) \\
5.1 \\
(3.8-6.4)\end{array}$ & $\begin{array}{c}(4.4-7.9) \\
1.0 \\
(0.7-1.2)\end{array}$ \\
\hline p value (Mann & Vhitney-U) & 0.01 & 0.01 \\
\hline $\begin{array}{l}\text { Previous } \\
\text { chemotherapy } \\
\text { p value (Mann }\end{array}$ & $\begin{array}{l}(n=11) \\
\text { (hitney-U }\end{array}$ & $\begin{array}{c}41.4^{*} \\
(35.9-55.1) \\
\text { n.s. }\end{array}$ & $\begin{array}{c}6.3^{* *} \\
(4.8-9.1) \\
\text { n.s. }{ }^{* *}\end{array}$ \\
\hline
\end{tabular}

Tumour vascularity was significantly reduced in CLM patients who responded compared with those who did not. However vascularity was not reduced where the tumour had become resistant following previous chemotherapy. Tumour vascularity may influence CLM response to Floxuridine where chemoresistance following previous 5-FU based therapy has not developed.
THE DISTRIBUTION OF SOMATOSTATIN RECEPTOR SUBTYPES IN NORMAL AND MALIGNANT COLONIC EPITHELIUM.

S.A.M. Laws, A.C. Gough, M.A. Bains \& J.N. Primrose University Department of Surgery, Southampton General Hospital. SO16 4YD

Somatostatin is a naturally occurring polypeptide that suppresses gut endocrine secretions and reduces cellular proliferation. It acts through five high affinity receptor subtypes coupled to G-proteins. Each receptor has differing binding affinities for ligand analogues and G-protein coupling therefore eliciting different intracellular responses.

In order to determine the role that somatostatin receptors may play in colon carcinogenesis, the five receptor subtype expression was determined by RT-PCR in 22 snap frozen surgical tumour-mucosa pairs and five metastases. In hSSTRI positive samples in situ hybridisation was performed using receptor specific probes.

Results : $77 \%$ of tumours and $68 \%$ mucosas expressed at least one SSTR subtype. 45\% tumours express hSSTR2 and $41 \%$ hSSTR1 the most frequently expressed receptors. hSSTR5 has not been described previously in the colon and was expressed in $27 \%$ tumours and $23 \%$ mucosal specimens. Only a two receptor subtypes were detected in any of the metastases (hSSTR 2 \& 5). In situ hybridisation showed that when present hSSTRl was distributed throughout the epithelium and not just in the endocrine cells.

Conclusion : Somatostatin receptors are expressed in a greater proportion of tumours than previously determined and hSSTR1 appears to be evenly distributed throughout the epithelium. Appropriate analogues targeted at specific receptor subtypes may have therapeutic potential.

RT-PCR $=$ Reverse transcription Polymerase chain reaction hSSTR = human somatostatin receptor subtype 
T145

IN VIVO STUDIES: SEX DIFFERENCES IN THE GROWTH OF GASTRO-INTESTINAL TUMOURS

E.Jacobs, S.A.Watson, J.D.Hardcastle, J.F.R.Robertson.

Department of Surgery, City Hospital, Nottingham.

There is a sex difference in the incidence of cancers at differing sites in the gastrointestinal (GI) tract. Some chemically induced tumours in animal models also show sex differences in their growth. Five human GI cancer cell lines were grown as xenografts in male and female immunodeficient mice.

In vivo, four of the five GI tumours grew faster in females than in males whether the mice were supplemented with oestradiol or not (significance by ANOVA $p=.000$ ). The effect of exogenous E2 on tumour growth was also significant (ANOVA $\mathrm{p}=.044$ ), being stimulatory in females and for 2 out of 4 cell lines in males.

\begin{tabular}{|c|c|c|c|c|}
\hline $\begin{array}{l}\text { cell-line } \\
\text { MKN45G } \\
\text { RD19 } \\
\text { Pan-1 } \\
\text { C146 } \\
\text { ApsL V* }\end{array}$ & $\begin{array}{c}\text { female } \\
\text { not tested } \\
1.46 \pm 0.78 \\
1.4 \pm 0.6 \\
2.56 \pm 0.49 \\
55 \pm 8\end{array}$ & $\begin{array}{c}\text { male } \\
\text { not tested } \\
1.4 \pm 0.12 \\
1.07 \pm 0.28 \\
2.09 \pm 1.03 \\
34 \pm 18\end{array}$ & $\begin{array}{c}\text { female+E2 } \\
1.7 \pm 1.2 \\
2.1 \pm .89 \\
2.2 \pm 0.7 \\
3.24 \pm 0.78 \\
57 \pm 18\end{array}$ & \\
\hline
\end{tabular}

There is a sex difference in the growth rate (both basal and E2 stimulated) of GI xenografts in nude mice. This finding has not been previously reported and highlights the risk that the efficacy of drug therapies may be either over- or underestimated if only one sex of animal is used.

\section{Gastroduodenal T147-T159} T147

A CONTROLLED STUDY OF ADRENALINE INJECTION IN PEPTIC ULCER BLEEDING WITHIN A SPECIALISED UNIT LMaseon, P Bramley, A Fraser, G McKnight, PW Brunt, A McKinlay, TS Sinclair, NAG Mowat. GI Unit, Aberdeen Royal Infirmary, Aberdeen

We have previously reported an overall mortality of $3.9 \%$ for upper GI bleeding, $5.3 \%$ for all peptic ulcers and $7 \%$ for peptic ulcers with Stigmata of Recent Haemorrhage (SRH), within a specialised Bleeding unit. Endoscopic intervention has been shown to improve rebleedirg and surgical rates, but few studies have taken into account the site of the ulcer or the timing of endoscopic therapy.

We evaluated the additional benefit of adrenaline injection in the standardised environment of a Bleeding Unit. From Oct '93-May '95 188 consecutive unselected patients were admitted with major peptic ulcer haemorrhage and SRH, 62 were actively bleeding and 126 nonactive bleeding (adherent fresh clot or non bleeding visible vessel). Patients were randomly allocated to adrenaline injection or control and were subsequently managed within the unit according to our established protocol. Both groups were well matched.

Observed reductions in rebleeding ( $13 \%$ v19\% - non active group only), surgical rate ( $21 \%$ v $33 \%)$, and blood transfusion (median units $3 \mathrm{v}$ 4 ) in the treatment group were not significant. The 30 day mortality was $4.3 \%(4 / 95)$ in the injection group and $6.3 \%(6 / 93)$ in the control, with a mean age for all deaths of 82 yrs. Surgical mortality was similar (15\% v $13 \%$ ) as was ulcer healing ( $90 \%$ in both groups).

Posterior DU, lesser curve GU and elderly patients did least well, and this was not influenced by injection therapy. However, in those whom the interval between the onset of bleeding and injection therapy was less than $24 \mathrm{hrs}$, the surgical referral was significantly reduced $(p<0.002)$

This, the largest controlled adrenaline study shows this treatment is safe but showed no significant benefit over optimal medical therapy within a specialised unit. We have identified a hitherto unrecognised subgroup with a short time from bleeding to admission who appear to benefit. In order to determine the best agent, optimal timing and which subgroup will benefit most larger studies are required, preferably in the controlled setting of a Bleeding unit
GASTRIMMUNE REDUCES LUNG METASTASES IN A HUMAN COLORECTAL MODEL

${ }^{1}$ S.A. Watson, ${ }^{4}$ D. Michaeli, ${ }^{1}$ T.M. Morris, ${ }^{2}$ A. Varro, ${ }^{3}$ G. Robinson, ${ }^{1}$ T.A.Justin and 1J.D. Hardcastle. ${ }^{1}$ Department of Surgery, The University of Nottingham, University Hospital, Nottingham UK, 2Physiological Department, The University of Liverpool, Liverpool UK, ${ }^{3}$ Department of Pathology, The University of Nottingham, University Hospital, Nottingham NG7 2UH and ${ }^{4}$ Aphton Corporation, Woodland, Califomia USA

Human colorectal tumours are known to be responsive to the proliferative effects of gastrin in a number of studies, leading to the evaluation of anti-gastrin compounds as potential therapeutic agents. One such agent is Gastrimmune, an immunogen composed of the $\mathbf{N}$ terminal of the 17 amino acid form of gastrin, G-17 linked to diphtheria toxoid (DT). Administration of Gastrimmune results in the production of specific, neutralising antibodies which bind both the amidated and the glycine-extended form of G17.

The human colorectal tumour line, APSLV, derived from a patient with advanced colorectal malignancy expressed CCKB/gastrin receptors on $90-95 \%$ of cells as evaluated by immunocytochemistry using an antiserum directed against an epitope of the receptor. The cell line also secreted $48 \mathrm{fmol} / 5 \times 10^{6}$ cells of progastrin peptide as measured in a radioimmune assay. The cell line was implanted into the muscle layer of the abdominal wall of SCID mice resulting in primary tumour growth and secondary spread to the lungs. The effect of intravenous infusion of antibodies raised by Gastrimmune immunisation was evaluated on the primary and secondary growth of APSLV tumours (control animals received antibodies raised by immunisation with DT only). Lung nodule number and cross-sectional area were assessed by image analysis of haematoxylin and eosin stained formalin fixed sections of the lungs .

The primary tumour cross-sectional area was $248 \mathrm{~mm}^{3}$ in the anti-DT antibody control group compared to $174 \mathrm{~mm}^{3}$ (30\% inhibition) in the anti-G17 treated test group ( $p=0.0334$, Mann Whitney). The median number of lung nodules in the control group was 3.5 compared to 1.0 ( $71 \%$ inhibition) in the test group ( $p<0.0001$, Mann Whitney). The cross-sectional area of the nodules present was $11.9 \mathrm{~mm}^{3}$ in the controls compared to $3.75(68.5 \%$ inhibition) in the test group $(\mathrm{p}=0.0064$, Mann Whitney). Thus, G17 neutralisation has modest growth effects on primary solid tumour growth but induces major inhibition of secondary spread.
EARLY FEEDING IN PATIENTS WITH BLEEDING PEPTIC ULCER AND A VISTBLE VESSEL - A CONTROLLED RANDOMISED TRIAL *C.C. Hepworth, M.Newton, S.Barton, E.Carty, "C.P.Swain, W.R.Burnham. Oldchurch Gastroenterology Unit, Romford, Essex and *GI Science Research Unit, Royal London Hospital, London, UK.

A controlled prospective randomised trial was undertaken of early feeding of bleeding peptic ulcer patients with a visible vessel, as this group of patients often remain fasted in case of surgery or repeat endoscopy. Patients were included if they had an ulcer with a non bleeding or oozing visible vessel (but excluded with spurting arterial haemorrhage). 130 patients were entered, 71 being randomised to receive normal diet and $50 \mathrm{mls}$ milk 2 hourly and 59 were randomised to be nil by mouth for 24 hours. The randomised patients were part of a total of 555 patients admitted with upper GI haemorthage over a 21 month period, 249 due to peptic ulcer disease, 99 having no visible vessels (one rebled after 1 day, required surgery and died), 130 had non bleeding or oozing visible vessels. 8 could not be randomised ( 2 had lost gag reflex, 3 were being ventilated, 1 went straight to theatre, 1 had gastric outlet obstruction, and 1 perforated). 12 patients were excluded because of spurting vessels at endoscopy. Endoscopic sclerotherapy consisted of adrenaline and ethanolamine within 24 hours of admission and repeated every 24 hours until the visible vessel had been obliterated. RESULTS 3/71 patients rebled randomised to food and milk ( 2 died) and $4 / 59$ patients rebled kept nil by mouth. There was no significant difference in: 1) the number of patients that rebled in either group ( $p=0.7$, Fisher's exact test) 2 ) in the mortality due to bleeding ( $2 / 71$ in the food group vs $3 / 59$ in the nil by mouth, $p=0.65$ ) and 3 ) in the number of patients requiring surgery $(1 / 71$ vs $4 / 59, p=0.17)$ Feeding was found not to impair repeat endoscopy. CONCLUSION Early feeding in this study was not shown to adversely affect outcome in bleeding peptic ulcer patients with a non bleeding or cozing visible vessel. 


\section{Reduced long term survival following major peptic ulcer haemorrhage}

\section{Kubba A K, Choudari C, Rajgopal C, Palmer K R}

GI Unit, Western General Hospital, Edinburgh

Correspondence to Mr A K Kubba, GI Annexe,

Western General Hospital, Crewe Road, Edinburgh, EH4 2XU

\section{Abstract}

The late outcome of patients who present with major peptic ulcer haemorrhage is largely unknown. We anticipated that prognosis may be poor because many such patients have severe co-morbid disease. 105 patients treated endoscopically for severe peptic ulcer haemorrhage were followed over a median period of 36 months (range 30-76 months), and outcome was compared with that of age and sex matched controls obtained from the Scotland mortality report of 1993. All patients had presented with major endoscopic stigmata of haemorrhage, age ranged between 30 and 96 years (median 68 years). $37 \%$ of patients had significant co-morbid disease. Kaplan-Mieir plots showed reduced survival in ulcer patients $(\mathrm{Z}<0.001)$. Deaths were largely restricted to patients who had co-morbid diseases; of the 27 patients who died, 19 succumbed from cardio-vascular disease, 5 had respiratory disease and 3 died from malignancy. Two died at home within 30 days of emergency ulcer surgery after failed endoscopic treatment. Seven of the remaining 79 patients had further peptic ulcer bleeding; 2 of these were taking maintenance acid reducing therapy. Data from a validated dyspepsia questionnaire showed that $83 \%$ of surviving patients had little or no dyspepsia, whilst four patients had severe dyspepsia despite appropriate ulcer medication. The late prognosis of patients who present with major ulcer haemorrhage is poor, but most deaths are a consequence of co-morbid disease and not recurrent ulcer bleeding. Most patients have little dyspepsia and many patients who rebled are free from dyspepsia.
DOES A PREVIOUS HISTORY OF DYSPEPSIA DELAY REFERRAL AND DIAGNOSIS FOR GASTRIC CANCER?

Suvakovic Z, Bramble MG, Wilson C, Jones RA, Idle N, Ruffett I.

Departments of Gastroenterology, Pathology and Cleveland FHSA, Middlesbrough General Hospital, Middlesbrough Cleveland TS5 5AZ.

Patients with gastric carcinoma usually have worrying symptoms such as anaemia, weight loss or dysphagia, by which time it is too late to offer effective surgical treatment. Studies of early gastric cancer emphasise that these patients have symptoms indistinguishable from benign disease. This study examined the FHSA held general practitioner records of patients dying from carcinoma of the stomach in the years 1991-1994. Previous gastrointestinal symptoms, excluding those leading up to referral and diagnosis, were compared to 200 age and sex related controls who died during the same period.

Results: Sixty three sets of general practitioner records were available for study. In total 47 patients had consulted their GP with previous dyspeptic symptoms giving a lifetime prevalence of $75 \%$. This compared to just $22 \%$ of age and sex matched controls who had also consulted their general practitioner with dyspepsia $(p<0.001)$. Previous investigation of symptoms was documented in 24 patients who had a barium meal examination and 11 patients had previously had a gastroscopy. Eighteen patients had documented ulcer disease ( 9 duodenal, 9 gastric). Five patients had a history of previous gastric surgery for peptic ulcer disease. In only 19 patients (30\%) was the diagnosis suspected by the general practitioner.

Conclusion: Patients with gastric cancer have a significant past medical history of dyspepsia, excluding the episode leading up to diagnosis. Previous investigation and an established diagnosis may delay referral for repeat investigation, even when symotoms change. Guidelines for gastroscopy need to reflect this possibility.

\section{IS IT NECESSARY TO TEST FOR HELICOBACTER PYLORI ERADICATION AFTER TREATMENT? \\ Johnston BJ, Reed PI \& Levi S. \\ Lady Sobell Gastrointestinal Unit, Wexham Park Hospital, Slough. Berks, SL2 4HL}

The use of a Gastrointestinal Symptom Rating Scale has been suggested (Phull et al 1995) to assess the success of Helicobacter pylori eradication therapy in duodenal ulcer patients. In a unit where ${ }^{13} \mathrm{C}$-urea breath tests (UBT) are used to monitor the effectiveness of H.pylori eradication therapy patients are questioned on symptom profile at the time of the UBT at least 1 month after the end of treatment. Symptoms were categorised into none, mild symptoms, symptoms pertaining to oesophageal reflux disease (GORD), or symptoms little changed or unchanged $(S)$. Patients were subdivided into duodenal ulcer disease (DU), gastric ulcer (GU) or non ulcer dyspepsia (NUD) and by whether the H.pylori had cleared (C) or persisted (P) according to UBT results.

\begin{tabular}{|l|c|c|c|c|c|c|c|c|}
\hline Diag. & \multicolumn{2}{|c|}{ None } & \multicolumn{2}{|c|}{ Mild } & \multicolumn{2}{c|}{ GORD } & \multicolumn{2}{|c|}{ S } \\
& C & P & \multicolumn{1}{|c|}{ C } & \multicolumn{2}{|c|}{ C } & \multicolumn{2}{c|}{ C } & P \\
\hline DU & 113 & 23 & 16 & 8 & 1 & 1 & 10 & 3 \\
\hline NUD & 11 & 6 & 5 & 3 & 0 & 0 & 7 & 3 \\
\hline GU & 9 & 1 & 0 & 1 & 0 & 0 & 1 & 0 \\
\hline
\end{tabular}

The positive predictive value of becoming H.pylori negative if totally asymptomatic post $H$. pylori eradication therapy was $81.6 \%$, negative predictive value $32.2 \%$, sensitivity $76.9 \%$ and specificity $38.9 \%$.

A significant proportion of DU patients $(23 / 35,66 \%)$ reported complete resolution of symptoms despite the failure of eradication treatment. It is noteworthy that the majority of NUD patients (12/23, $52 \%$ ) had little change in the symptom profile post-treatment despite H.pylori eradication

We conclude that it is important to accurately re-determine the H.pylori status of patients after eradication treatment to avoid inappropriate withdrawal of maintenance therapy with $\mathrm{H}_{2}$ antagonists.

Conclusion: Of the 1.2\% Melton GP population on repeat acid suppressant treatment, $32 \%$ had confirmed peptic ulcer disease. Dual therapy is effective in $H$.pylori eradication in the community. It is recommended that peptic ulcer disease patients in the community on long term acid suppressant treatment be treated with a course of $\boldsymbol{H}$.pylori eradication therapy. 
H. pylori ERADICATION AND GASTRIC ACID SECRETION: A 12 MONTH FOLLOW-UP STUDY IN DU SUBJECTS

JA Louw, GO Young S Bridger, W Lucke and IN Marks. Gastrointestinal Clinic and Department of Medicine, Groote Schuur Hospital and University of Cape Town.

The effect of $H$. pylori eradication on gastric secretion is controversial. It has been postulated that the hypergastrinaemia associated with antral $H$. pylori gastritis may lead to an increased parietal cell mass (PCM). If so, eradication of $H$. pylori would be expected to be associated with a decrease in acid secretion. While studies using Gastrin Releasing Peptide (GRP) as a stimulus have indicated a reduction in acid secretion following eradication, studies with gastrin as secretagogue have shown no consistent pattern. Data on longer term follow-up is, however, limited. We report on the effect of $H$. pylori eradication on gastric secretory status, both immediately following eradication and 12 months later.

Patients and Methods: Patients with active duodenal ulceration were randomly allocated to healing with sucralfate or ranitidine. Following healing, $H$. pylori was eradicated with bismuth based "Triple Therapy". Gastric secretion was assessed before therapy, following healing, following eradication and 12 months later. Gastric acid output was measured for basal (Bas), low dose (LD; $0.1 \mu \mathrm{g} / \mathrm{kg}$ ) and high dose (HD; $6 \mu \mathrm{g} / \mathrm{kg}$ ) pentagastrin stimulation. Nonparametric statistical analysis was used.

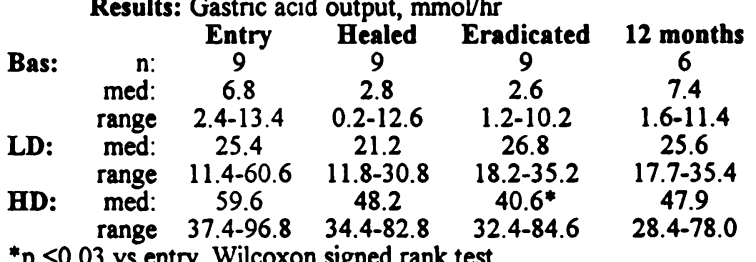

$* p<0.03$ vs entry, Wilcoxon signed rank test.

Conclusion: This long-term follow-up study showed no consistent reduction in gastrin stimulated gastric acid secretion following $H$. pylori eradication. Since the acid secretory response to maximal gastrin stimulation reflects parietal cell mass, these data suggest that $H$. pylori eradication is not associated with a reduction in parietal cell mass.
PARIETAL CELL SENSITIVITY TO GASTRIN DISTINGUISHES $H$ PYLORI INFECTED DU PATIENTS FROM NIFECTED HEALTHY VOLUNTEERS

Gillen D, El-Omar E, McColl K E L. University Dept. of Medicine \& Therapeutics, Westem Infirmary, Glasgow, Scotland.

Backoround: It is unclear why $H$ pylori produces duodenal ulceration in only a minority of infected subjects. In all subjects it increases gastrin release and the magnitude of this is similar in those with and without DU. We have investigated whether those who develop DU are more sensitive to the acid stimulatory effects of gastrin.

Patients and Methods: Eighteen $\mathrm{H}$ pylori negative and $13 \mathrm{H}$ pylori-positive healthy volunteers (HV) and $10 H$ pylori positive DU patients were examined. Each group was matched for age, sex and weight. After a $30 \mathrm{~min}$ basal period, gastrin 17 was infused i.v. in doses of $7,20,60,180$ and $800 \mathrm{pmol} / \mathrm{kg} / \mathrm{hr}$ over consecutive 30 minute periods. Gastric juice was collected in 30 minute aliquots and acid outputs determined. Sensitivity was determined by calculating the $\mathbf{G 1 7}$ dose required to produce half maximal acid response (D50)

Results: None of the groups showed a statistically significant difference in maximum acid output (MAO) to G17. However, $H$ pylori positive HVs were less sensitive to gastrin than $H$ pylori negative HVs $(\mathrm{p}<0.046)$. In addition, the $H$ pylori positive DU patients were more than twice as sensitive to gastrin compared to $H$ pylori positive HVs $(\mathrm{p}<0.002)$ and produced more than twice the acid in response to submaximal $\mathrm{G} 17(20 \mathrm{pmol} / \mathrm{kg} / \mathrm{h})(\mathrm{p}<0.025)$.

\begin{tabular}{|c|c|c|c|}
\hline $\begin{array}{l}\text { median MAO to } \mathrm{G} 17 \\
\text { in } \mathrm{mmo} / \mathrm{hr} \text { (range) }\end{array}$ & $\begin{array}{c}\text { HP-ve HVs } \\
38.2 \\
(21.8-62.0)\end{array}$ & $\begin{array}{c}\text { HP+ve HVs } \\
35.9 \\
(18.6-54.8)\end{array}$ & $\begin{array}{c}H P+\text { ve DUs } \\
48.6 \\
(16.8-61.3)\end{array}$ \\
\hline G17 D50 in pmol/kg/h & $\begin{array}{c}15.0 \\
(8.0-45.5)\end{array}$ & $\begin{array}{c}24.2 \\
(11.0-68.0)\end{array}$ & $\begin{array}{c}9.9 \\
(3.0-20.5)\end{array}$ \\
\hline $\begin{array}{l}\text { acid output } \\
\text { (mmol/h) to G17 } \\
20 \mathrm{pmol} / \mathrm{kg} / \mathrm{h}\end{array}$ & $\begin{array}{c}22.4 \\
(7.9-44.4)\end{array}$ & $\begin{array}{c}14.9 \\
(5.2-35.0)\end{array}$ & $\begin{array}{c}33.8 \\
(9.3-43.9)\end{array}$ \\
\hline
\end{tabular}

Conclusion: Sensitivity to gastrin is a key factor in determining which $H$ pylori infected patients develop duodenal ulcers.
THE PREVALENCE AND EXTENT OF GASTRIC METAPLASIA IN THE DUODENAL BULB ARE NOT RELATED TO H. PYLORI AW Harris, MM Walker, JH Baron, JJ Misiewicz. Parkside Helicobacter Study Group, Central Middlesex \& St Mary's Hospitals, London, UK.

Gastric metaplasia in the duodenal bulb (DGM) is more common and greater in extent in $H$. pylori (Hp) +ve patients with duodenal ulcer (DU) than in $\mathrm{Hp}$-ve healthy controls. We have reported that there was a significant direct relationship between the extent of DGM \& acid output. Hp +ve DU have increased pentagastrin $(\mathrm{Pg})$-stimulated peak acid output $\left(\mathrm{PAO}_{\mathrm{F}}\right)$, and this may contribute to the effect of $\mathrm{Hp}$ on DGM. However, we also found that neither the presence nor extent of DGM were significantly changed six months after $\mathrm{Hp}$ eradication in patients with $\mathrm{DU}$, despite a significant decrease $(33 \%)$ in $\mathrm{PAO}_{\mathrm{P}_{\mathrm{g}}}$. Previous studies suggest that prolonged ( $>6$ months) \& profound hypochlorhydria ( $>90 \%$ decrease in $\mathrm{PAO}_{\mathrm{P}}$ ) are necessary to decrease the extent of DGM. Here our aim was to measure prevalence and extent of DGM in Hp +ve \& Hp -ve DU, in order to determine the importance of $\mathrm{Hp}$ in the pathogenesis of DGM in patients with acid hypersecretion and DU

We have studied 19 patients with endoscopic DU. There were $10 \mathrm{Hp}$ tve (7 men, mean age 37, range 22-58) DU, $6 \mathrm{Hp}$-ve ( 5 men, mean age 40 , range 26-53) recurrent $\mathrm{DU}>6$ months after Hp eradication, and $3 \mathrm{Hp}$-ve (2 men, mean age 46, range 33-55) DU (never infected). None had taken NSAIDs. Hp status was determined by histology \& culture of antral \& body biopsies and by ${ }^{13} \mathrm{C}$ UBT, and classified as $\mathrm{Hp}$ +ve on any +ve result, and Hp -ve on all three tests -ve. Quadrantic biopsies were taken from the duodenal bulb \& stained with PAS. Presence \& extent of DGM was measured blindly using a computer-enhanced image intensifier. Extent of DGM was calculated as $\%$ of the total epithelial surface measured in each biopsy.

DGM was found in 9 of $10 \mathrm{Hp}+\mathrm{ve} \mathrm{DU}, 5$ of $6 \mathrm{Hp}$-ve recurrent DU and 3 of $3 \mathrm{Hp}$-ve DU ( $>0.05)$. The extent (median, range \%) of DGM was 38 (0-53), $26(0-97)$ and 54 (2-62) in Hp +ve DU, Hp -ve recurrent DU and Hp -ve DU ( $p>0.05)$, respectively.

We conclude that the prevalence \& extent of DGM are not related to Hp in patients with DU. These findings do not support the model that $\mathrm{Hp}$ is involved in the pathogenesis of DGM in patients with DU. Rather, high acid response to $\mathrm{Pg}$, which is present in $\mathrm{Hp}+\mathrm{ve}$ and -ve $\mathrm{DU}$, may be important
Comparison of serum, salivary and rapid whole-blood diagnostic tests for Helicobacter pylori and their validation against endoscopybased tests.

TG Reilly DSA Saunders ${ }^{\dagger}$, T Elliott ${ }^{\ddagger}$ \& RP Walt. Departments of Medicine, 'Histopathology \& 'Microbiology, Queen Elizabeth Hospital, Birmingham.

Introduction: We wished to assess the suitability for screening of a new rapid whole-blood test (RWBT) and a salivary assay (Helisal Cortecs), by testing their relative abilities and those of two ELISA serology kits (Helico-G and Cortecs) to correctly predict the presence of $H$. pylori, as validated against slide urease, ${ }^{13} \mathrm{C}$-urea breath test and histology.

Method: 303 consecutive dyspeptic patients attending for gastroscopy underwent two antral biopsies for histology, and one for slide urease test (CLOtest ${ }^{\circ}$ ). After endoscopy $7 \mathrm{ml}$ blood was taken for serology, and saliva was collected by absorbent pad. 100 patients also took a ${ }^{13} \mathrm{C}$-urea breath test.

Results: True positives were defined as those with a positive CLOtest ${ }^{\circ}$, or histology, or ${ }^{13} \mathrm{C}$-urea breath test, or more than one of these, and true negatives as those with none of these. 300 patients (median age 63, range 28-89) were eligible for analysis. There were 163 true positives of which RWBT identified 107, Helico-G 145 , Cortecs 148, and salivary assay 127 , and 137 true negatives of which the number falsely identified as positive was 30 by RWBT, 42 by Helico-G (cut-off $11 \mathrm{U} / \mathrm{ml}$ ), 40 by Cortecs serology, and 41 by salivary assay. Sensitivities, specificities and positive (PPV) and negative (NPV) predictive values are shown below.

\begin{tabular}{lllll} 
& \multicolumn{2}{l}{ Sensitivity (95\% CI) Specificity (95\% CI) } & PPV & NPV \\
RWBT & $77.9(71-84)$ & $78.1(71-85)$ & $78 \%$ & $78 \%$ \\
CLOtest & $90.8(85-95)$ & $100.0(97-100)$ & $100 \%$ & $92 \%$ \\
Histology & $89.5(85-94)$ & $100.0(97-100)$ & $100 \%$ & $91 \%$ \\
13C-UBT & $86.7(75-94)$ & $100.0(91-100)$ & $100 \%$ & $88 \%$ \\
Helico-G & $89.0(84-93)$ & $69.3(61-77)$ & $74 \%$ & $86 \%$ \\
Cortecs serum & $90.8(85-95)$ & $70.8(63-78)$ & $76 \%$ & $88 \%$ \\
Cortecs saliva & $78.9(73-85)$ & $69.9(62-78)$ & $72 \%$ & $77 \%$
\end{tabular}

Conclusion: The positive predictive value of the rapid whole-blood test Concluaion: The positive predictive value of the rapid whole-blood test a low negative predictive value. The salivary assay had low sensitivity and specificity. 
NESTED-POLYMERASE CHAIN REACTION (PCR) FOR THE DETECTION OF HELICOBACTER PYLORI IN GASTRIC BIOPSY SAMPLES.

MM Ozmen, AC Gough, P Sarsfield* CD Johnson

University Surgical Unit, *Histopathology, Southampton General Hospital Southampton.

$\mathrm{H}$ pylori is a fastidious organism strongly associated with gastric disease. A variety of protocols have been developed for its detection. Of these histology and culture have been considered the most specific, whereas the CLO-test is more sensitive. Nested-.PCR is highly sensitive and specific for detection of small numbers of cells. The aim of this study was to compare the efficiency of nested PCR, CLO-test and histology in the diagnosis of $\mathrm{H}$ pylori infection.

41 dyspeptic patients (25M, 16F) median (range) age 54 (31-83) years, who had endoscopy were studied. No patient had peptic ulceration. All assays, CLO-test, histology and PCR were performed on biopsies obtained from the gastric antrum. The same sample was used for both CLO-test and nested PCR

$22(54 \%), 19(50 \%)$ and $35(85 \%)$ samples were positive by CLOtest, histology (3 missing) and nested PCR respectively. 23 samples were positive by PCR and one or both of histology and CLO-test. 12 samples were negative to both histology and CLO-test, but positive to PCR. Six samples were negative on all three tests and no sample was negative to nested PCR and positive for another test. If CLOtest/histology is taken as the standard, nested PCR has a sensitivity of $100 \%$ and specificity of $65 \%$. If nested PCR is the standard, CLOtest/histology has a sensitivity of $65 \%$ and a specificity of $100 \%$.

False negative results with CLO-test and histology may result from scanty infection. The power of nested PCR to detect small numbers of organisms may explain positive results in these cases. However, minute amounts of contaminating material can give false positive results with PCR. Provided that care is taken to prevent contamination during sampling and DNA extraction, nested PCR seems a good candidate for gold standard status in the diagnosis of $\mathrm{H}$ pylori infection.
T159

\section{A STUDY OF THE RELATIONSHIP BETWEEN ALCOHOL} INTAKE AND GASTRIC LUMINAL ANTIOXIDANT CONCENTRATIONS. ZW Thane, SE Patchett, D Pertet, MUG Farthing. Digeative Diseases Reacarch Centre and Dept of Medicine, Medical College of St Bartholomew's Hospital, London, UK.

Epidemiological studies have suggested that there is a relationship between alcohol consumption and the development of gastric cancer. Adequate intake of anti-oxidants (vitamins C, E, and B-carotenc) may be protective against gastric cancer and the levels in gastric juice may be particularly important. We therefore measured gastric luminal vitamins C, E, and B-carotene concentrations and examined whether they are influenced by alcohol intake.

Anti-oxidant concentrations were determined in gastric juice obtained at upper gastrointestinal endoscopy in consecutive patients (vitamin $C$ $n=63$, vitamin $E \mathrm{n}=68, \beta$-carotene $n=59$ ). All values were measured in duplicate using HPLC/electrochemical detection and expressed as median [interquartile range]. Patients were interviewed with regard to their alcohol and cigarette consumption prior to endoscopy. Levels of alcohol consumed was graded as none, $<21,21-42$ and $>42$ units/week. Cigarette consumption was similarty recorded as none, $<10,10-20$ and $>20$ cigarettes/day.

The levels of each anti-oxidant in gastric juice were unaffected by the underlying endoscopic diagnosis. When controlled for age and sex, alcohol drinkers had significantly lower $\beta$-carotene in gastric juice than non-drinkers, 3.12nM [0-4.78] vs $3.92[2.91-6.61],(p<0.01)$. The $\beta$ carotene level was inversely related to the amount of alcohol consumed $(r=-0.32, p<0.02)$. No relationship between alcohol consumption and vitamin $C$ or $E$ level was evident. Furthermore there was no association between smoking and the levels of any of these anti-oxidants regardless of the number of cigarettes smoked.

Alcohol intake would appear to be a determinant of gastric juice $\beta$ carotene concentration but not of vitamin $C$ or $E$. The adverse effects of alcohol consumption on $\beta$-carotene levels may have implications for gastric cancer development particularly in subjects with high alcohol intake.

\section{IBD and AIDS F160-F163}

F160

TRANSDERMAL NICOTINE COMPARED WITH ORAL PREDNISOLONE FOR ACTIVE ULCERATIVE COLITIS. GAO Thomas, 'J Rhodes,' $\mathrm{K}$ Ragunath, ${ }^{2} \mathrm{~V}$ Mani, ${ }^{2} \mathrm{G}$ Williams, ${ }^{,} \mathrm{R}$ Newcombe, ${ }^{1}$ MAH Russell, ${ }^{3} \mathrm{C}$ Feyerabend. ${ }^{3}$ Dept of Gastroenterology, UHW, Cardiff,' Leigh Infirmary, Manchester. 'Institute of Psychiatry, Kings Hospital, London. ${ }^{3}$

Ulcerative colitis (UC) is largely a disease of non-smokers. Controlled trials have shown benefit with transdermal nicotine (TN) given with 5-aminosalicylic acid (5-ASA) in active disease but not when given alone as maintenance therapy. We examined $\mathrm{TN}$ alone compared with prednisolone in active disease.

Methods: 61 patients with active UC were given either TN or 15 mg prednisolone for 6 weeks in a randomised, double-blind study. Incremental doses of TN were given for the first 9 days; patients tolerated 15 to $25 \mathrm{mg} / 16$ hours. Most were taking 5-ASA at entry which was stopped at 9 days, a few taking topical steroids stopped these at the onset. Clinical, sigmoidoscopic and histological assessments were made at entry and at 6 weeks, or at premature withdrawal. Side-effects and serum nicotine and cotinine concentrations were monitored throughout.

Results: 43 completed the trial. Of these, 6 of 19 on TN achieved full sigmoidoscopic remission compared with 14 of 24 on prednisolone $(p=0.08)$. In those who completed the study, there was significant improvement with both $\mathrm{TN}$ and prednisolone for the $\mathrm{St}$ Marks score $(p<0.05$ and $p<0.001$, respectively), Global Clinical Grade ( $p<0.01$ for both), and sigmoidoscopic score $(p<0.01$ and $p<0.001$ ), differences between groups favour prednisolone, but none reach statistical significance. Those on TN had more withdrawals ,11 versus 7 respectively, both for deterioration (6 vs 5) and for side-effects (5 vs 2) Side-effects were more frequent on TN than prednisolone ( 44 vs $19 ; p=0.03$ ), the most common of which were, nausea, lightheadedness and tremor.

Conclusion: Nicotine alone was of benefit in acute colitis, but 15 $\mathrm{mg}$ of prednisolone was more effective. IL8, $H$ pylori sonicates from 2 out of 4 strains stimulated gastrin release in a dose dependent manner: producing a maximal stimulation of $232 \pm 33 \%$ above basal:p<0.05). Viability was unimpaired.

Conclusions. The inflammatory cytokine IL8 can stimulate gastrin release from G- cells, this effect can be potentiated by Hp products. An interaction between cytokines and $\mathrm{Hp}$ products may contrilbute to the hypergastriaemia seen in vivo. 